OPEN ACCESS

Edited by:

Sang Yeol Lee,

Gyeongsang National University,

South Korea

Reviewed by:

Honghong Wu,

University of California, Riverside,

United States

María Serrano,

Universidad Miguel Hernández

de Elche, Spain

*Correspondence:

Branka Salopek-Sond

salopek@irb.hr

${ }^{t}$ These authors have contributed equally to this work as first authors

Specialty section: This article was submitted to

Plant Abiotic Stress,

a section of the journal

Frontiers in Plant Science

Received: 23 December 2018 Accepted: 25 March 2019

Published: 11 April 2019

Citation:

Pavlović I, Mlinarić S,

Tarkowská D, Oklestkova J, Novák O,

Lepeduš H, Vujčcić Bok V,

Radić Brkanac S, Strnad M and

Salopek-Sondi B (2019) Early

Brassica Crops Responses to Salinity

Stress: A Comparative Analysis

Between Chinese Cabbage, White

Cabbage, and Kale.

Front. Plant Sci. 10:450.

doi: 10.3389/fp/s.2019.00450

\section{Early Brassica Crops Responses to Salinity Stress: A Comparative Analysis Between Chinese Cabbage, White Cabbage, and Kale}

Iva Pavlović1,2†, Selma Mlinarić ${ }^{3 \dagger}$, Danuše Tarkowská2, Jana Oklestkova ${ }^{2}$, Ondřej Novák², Hrvoje Lepeduš ${ }^{4,5}$, Valerija Vujčić Bok ${ }^{6}$, Sandra Radić Brkanac ${ }^{6}$, Miroslav Strnad ${ }^{2}$ and Branka Salopek-Sondi* ${ }^{*}$

${ }^{1}$ Department of Molecular Biology, Ruđer Bošković Institute, Zagreb, Croatia, ${ }^{2}$ Laboratory of Growth Regulators, Institute of Experimental Botany, The Czech Academy of Sciences, Palacký University, Olomouc, Czechia, ${ }^{3}$ Department of Biology, Josip Juraj Strossmayer University of Osijek, Osijek, Croatia, ${ }^{4}$ Faculty of Humanities and Social Sciences, Josip Juraj Strossmayer University of Osijek, Osijek, Croatia, ${ }^{5}$ Faculty of Dental Medicine and Health, Josip Juraj Strossmayer University of Osijek, Osijek, Croatia, ${ }^{6}$ Division of Botany, Department of Biology, Faculty of Science, University of Zagreb, Zagreb, Croatia

Soil salinity is severely affecting crop productivity in many countries, particularly in the Mediterranean area. To evaluate early plant responses to increased salinity and characterize tolerance markers, three important Brassica crops - Chinese cabbage (Brassica rapa ssp. pekinensis), white cabbage (B. oleracea var. capitata) and kale (B. oleracea var. acephala) were subjected to short-term $(24 \mathrm{~h})$ salt stress by exposing them to $\mathrm{NaCl}$ at concentrations of 50,100 , or $200 \mathrm{mM}$. Physiological (root growth, photosynthetic performance parameters, and $\mathrm{Na}^{+} / \mathrm{K}^{+}$ratio) and biochemical parameters (proline content and lipid peroxidation as indicated by malondialdehyde, MDA, levels) in the plants' roots and leaves were then measured. Photosynthetic parameters such as the total performance index $\mathrm{Pl}_{\text {total }}$ (describing the overall efficiency of PSI, PSII and the intersystem electron transport chain) appeared to be the most salinity-sensitive parameter and informative stress marker. This parameter was decreased more strongly in Chinese cabbage than in white cabbage and kale. It indicated that salinity reduced the capacity of the photosynthetic system for efficient energy conversion, particularly in Chinese cabbage. In parallel with the photosynthetic impairments, the $\mathrm{Na}^{+} / \mathrm{K}^{+}$ratio was highest in Chinese cabbage leaves and lowest in kale leaves while kale root is able to keep high $\mathrm{Na}^{+} / \mathrm{K}^{+}$ratio without a significant increase in MDA. Thus $\mathrm{Na}^{+} / \mathrm{K}^{+}$ratio, high in root and low in leaves accompanying with low MDA level is an informative marker of salinity tolerance. The crops' tolerance was positively correlated with levels of the stress hormone abscisic acid (ABA) and negatively correlated with levels of jasmonic acid (JA), and jasmonoyl-L-isoleucine (JA-lle). Furthermore, salinity induced contrasting changes in levels of the growthpromoting hormones brassinosteroids (BRs). The crop's tolerance was positively correlated with levels of BR precursor typhasterol while negatively with the active BR 
brassinolide. Principal Component Analysis revealed correlations in observed changes in phytohormones, biochemical, and physiological parameters. Overall, the results show that kale is the most tolerant of the three species and Chinese cabbage the most sensitive to salt stress, and provide holistic indications of the spectrum of tolerance mechanisms involved.

Keywords: Chinese cabbage, kale, salinity stress, photosynthetic performance, stress hormones, brassinosteroids, tolerance, white cabbage

\section{INTRODUCTION}

Global warming and associated climate changes are imposing severe abiotic stresses that are seriously impairing crop yields and quality in many affected areas. One of these stresses (exacerbated by various human activities) is soil salinity. Over $7 \%$ of the world's total land and approximately $20 \%$ of irrigated land is affected by high salinity. The problem is particularly severe in the Mediterranean, semi-arid and arid areas (Zhang et al., 2014; Munns and Gilliham, 2015).

Plants' growth rates and productivity depend on photosynthetic efficiency. Thus, it is highly important for them to adjust their photosynthetic apparatus in accordance with environmental stresses. Photosystem II (PSII) is the most sensitive part of the apparatus to salt stress (Kalaji et al., 2011; Jajoo, 2014; Oukarroum et al., 2015). However, salinity stress has complex effects on photosynthetic activity, depending on the species or cultivar, duration of the stress and salt concentration. Low salt concentrations usually induce adaptations of photosynthetic activity, overall connectivity of the photosystem units and functional antenna size that maintain or even increase photosynthetic efficiency (Mehta et al., 2010; Dąbrowski et al., 2016). In contrast, higher salinity usually causes photoinhibition of both photosystems (PSII and PSI), inhibits overall electron transport chain activity and increases non-photochemical quenching (Jajoo, 2014).

Salt concentrations exceeding taxa-specific thresholds induce three kinds of interacting stresses that are collectively called salinity stress. These are ionic stress caused by toxic concentrations of ions (mainly $\mathrm{Na}^{+}$), osmotic stress caused by associated reductions in water uptake, and oxidative stress mainly driven by increases in levels of reactive oxygen species (ROS) (Liang et al., 2018). Energy-efficient osmotic adjustment of cell turgor by the accumulation of $\mathrm{Na}^{+}$and $\mathrm{Cl}^{-}$in leaves and roots is a characteristic response of salt-tolerant species and halophytes. In addition, maintaining low $\mathrm{Na}^{+}$(and $\mathrm{Cl}^{-}$) concentrations in the cytoplasm of cells, optimizing the concentration of essential $\mathrm{K}^{+}$and efficient sequestration of salt ions in vacuoles are key elements of "tissue tolerance" (Munns et al., 2016). In fact, $\mathrm{Na}^{+}$competing with the binding site of $\mathrm{K}^{+}$on proteins e.g., channels and enzymes, is the main reason for $\mathrm{Na}^{+}$toxicity (Almeida et al., 2017). High $\mathrm{Na}^{+}$concentrations in cellular cytoplasm can inactivate enzymes and metabolic processes. Furthermore, the accumulation of $\mathrm{Na}^{+}$in leaves can inhibit photosynthesis if ions are not adequately compartmentalized at the cellular or subcellular level (Julkowska and Testerink, 2015). Moreover, more salt-sensitive species respond by de novo synthesis of osmolytes and allocation of growth assimilates to osmotic adjustment, with consequent increases in energy costs and reductions in growth rates (Munns et al., 2016). In addition, the oxidative stress associated with high salinity necessitates induction of antioxidant mechanisms to detoxify ROS, as inefficient ROS removal can result in damage to essential macromolecules (proteins, lipids, and nucleotides) and cell death.

One of the key mediators and modulators of plants' responses to all environmental factors are phytohormones, the main plant signaling molecules (Verma et al., 2016; Raja et al., 2017). Complex networks of interacting phytohormones [abscisic acid (ABA), salicylic acid, jasmonates (JAs), brassinosteroids (BRs), cytokinins, ethylene, auxins, and gibberellins] play crucial roles in plants' physiological responses and adaptation to salinity stress (Fahad et al., 2015). One of these phytohormones, ABA, is a key mediator of osmotic stress responses (Fahad et al., 2015). ABA regulates transpiration rates and maintains cellular turgor by controlling stomatal opening and closure (in concert with other phytohormones), induces osmoprotectant accumulation, activates ROS detoxification mechanisms, and modifies ion transport (Finkelstein, 2013; Fahad et al., 2015). JAs also modulate plants' growth, development and abiotic stress responses (Ahmad et al., 2016). They play key roles, inter alia, in the development of embryos, seedlings and floral organs, seed germination, growth inhibition, and senescence. JAs also participate interactively with other phytohormones in crops' performance affecting adaptations to changes in environmental conditions (Per et al., 2018). Inter alia, crosstalk between $\mathrm{ABA}$ and JAs regulates stomatal closure and transpiration under drought conditions, and in saline conditions, JAs are involved in the control of uptake of sodium ions (Riemann et al., 2015). BRs also have been recently reported roles in plant tolerance to diverse stress factors (e.g., salt, drought, and temperature stresses) (Jiroutova et al., 2018). BRs participate in the control of cell cycling and growth, modification of cell wall architecture, and adjustment of membrane systems. Moreover, they contribute to the maintenance of cells' redox systems and the regulation of stomatal aperture in drought and salinity responses (Sharma et al., 2017).

To meet problems caused by salinity, knowledge of major crops' tolerance levels and mechanisms is clearly important. Currently, most Brassica crop species are classified as moderately salt tolerant. However, the amphidiploid species B. juncea, $B$. napus, and $B$. carinata reportedly have a somewhat higher tolerance than the diploids $B$. oleracea, $B$. nigra, and $B$. rapa (Purty et al., 2008). The reasons for this are uncertain, and there is little knowledge of tolerance mechanisms in the family. To assist 
efforts to elucidate mechanisms responsible for salt tolerance in Brassicaceae, three Brassica crops with global economic importance were selected for this study: white cabbage (Brassica oleracea var. capitata), kale (B. oleracea var. acephala), and Chinese cabbage (B. rapa L. pekinesis). Given the complexity of tolerance mechanisms, a holistic approach was chosen in efforts to elucidate salinity responses of the three Brassica crops.

We hypothesized that early, initial salinity responses may be essential for long-term salinity tolerance and provide insights into the involvement of different defense mechanisms. Moreover, we hypothesized that fine tuning of hormonal status plays major roles in early salt stress responses and further adaptation of the selected brassicas. We first determined their sensitivity/tolerance to applied salinity stresses by root-growth bioassays and biomass production. Then photosynthetic parameters of hydroponically grown plants were measured following short-term salinity stress. In parallel, biochemical parameters involved in responses to oxidative stress (the level of lipid peroxidation), osmotic stress (proline accumulation), and ionic stress $\left(\mathrm{Na}^{+} / \mathrm{K}^{+}\right.$ratio) were measured in leaves and roots of treated plants in comparison to corresponding controls. We also measured changes in levels of $\mathrm{ABA}$, JAs, and $\mathrm{BRs}$ to explore their roles in the regulation of salinity responses in the selected crops. Finally, Principal Component Analysis (PCA) of acquired data enabled us to draw correlations regarding traits of the crops and identify key contributors to differences in their salinity responses.

\section{MATERIALS AND METHODS}

\section{Plant Material and Experimental Conditions}

Seeds of Chinese cabbage (B. rapa L. ssp. pekinensis (Lour.) Hanelt cv. Cantonner Witkrop), white cabbage (B. oleracea var. capitata cv. Varaždinski) and kale (B. oleracea var. acephala cv. IJK9) were purchased from ISP International Seed Processing $\mathrm{GmbH}$, Quedlinburg, Germany, the Agricultural Advisory Service of Varaždin Region, Croatia, and Institute for Adriatic Crops and Karst Reclamation, Split, Croatia, respectively.

The level of salinity tolerance/sensitivity of the selected Brassica crops was determined using the root-growth bioassay described by Pavlović et al. (2018a). The effect of $\mathrm{NaCl}$ on the seedlings biomass production was evaluated after 7 days of treatments in comparison to the corresponding controls.

For hydroponic growth, seeds were germinated on 1\% agar plates and then several-day-old seedlings were placed in a home-made hydroponic growth system supplying commercially available nutrient solutions (Flora Series and GHE Hydroponics) according to the manufacturers' instructions. Plants were grown in $5.5 \mathrm{~L}$ dark pots in a growing chamber at $21^{\circ} \mathrm{C}$, with $16 / 8 \mathrm{~h} \mathrm{light}$ $\left(115 \mu \mathrm{mol} \mathrm{m}^{-2} \mathrm{~s}^{-1}\right) /$ dark cycles.

At the four fully developed leaf stage (after 3-4 weeks, depending on the cultivar) sets of the plants were subjected to salinity stress, by incrementally increasing concentrations of $\mathrm{NaCl}$ for $25 \mathrm{mM}$ and $50 \mathrm{mM}$ in the nutrient solution (in order to avoid shock). Salinization was performed at $2 \mathrm{~h}$ intervals to final concentrations as follows: $50 \mathrm{mM} \mathrm{NaCl}$ (25 mM/two steps),
$100 \mathrm{mM} \mathrm{Na}$ (25 mM/four steps), and $200 \mathrm{mM} \mathrm{NaCl}$ (25 mM/four steps and $50 \mathrm{mM} /$ two steps), respectively. The nutrient solution of controls of each species remained unchanged. After $24 \mathrm{~h}$ of exposure to the final salt concentrations, the plants were harvested together with controls. The experiment was performed with four biological replicates, each consisting of eight plants from a pot, unless otherwise stated.

Plant material for biochemical analysis was stored at $-80^{\circ} \mathrm{C}$ until use while material for hormonal profiling and determination of ion contents was freeze-dried until analysis. Photosynthesis measurements (fast chlorophyll $a$ fluorescence kinetics) were performed on leaves in vivo, as described below.

\section{Fast Chlorophyll a Fluorescence Kinetics}

Fast chlorophyll a fluorescence kinetics were measured on 18 randomly selected, dark-adapted leaves of each Brassica cultivar using a Handy-PEA fluorimeter (Hansatech, United Kingdom). After $30 \mathrm{~min}$ of dark adaptation, the leaves were exposed to a pulse of saturating red light $(3200 \mu \mathrm{mol}$ $\mathrm{m}^{-2} \mathrm{~s}^{-1}$, peak at $\left.650 \mathrm{~nm}\right)$. OJIP transients were measured by recording data from $50 \mu \mathrm{s}\left(\mathrm{F}_{0}\right)$ to $1 \mathrm{~s}\left(\mathrm{~F}_{\mathrm{m}}\right)$. Data extrapolated from the acquired OJIP curves were subjected to JIP-tests to calculate parameters according to Strasser et al. (2000). Calculations are shown in Supplementary Table S1.

The OJIP transients were double-normalized between $\mathrm{O}$ $(50 \mu s)$ and $\mathrm{P}$ steps and presented as relative variable fluorescence, $\mathrm{W}_{\mathrm{OP}}=\left(\mathrm{F}_{\mathrm{t}}-\mathrm{F}_{0}\right) /\left(\mathrm{F}_{\mathrm{P}}-\mathrm{F}_{0}\right)$. Fluorescence data were plotted on a logarithmic time scale, and the $\mathrm{O}, \mathrm{J}$, I, and $\mathrm{P}$ steps were marked in plots. Normalization between $\mathrm{O}$ and $\mathrm{K}(300 \mu \mathrm{s})$ steps revealed L-band (150 $\mu \mathrm{s})$ which was presented as variable fluorescence $\mathrm{W}_{\mathrm{OK}}=\left(\mathrm{F}_{\mathrm{t}}-\mathrm{F}_{0}\right) /\left(\mathrm{F}_{\mathrm{K}}-\mathrm{F}_{0}\right)$ and then plotted with difference kinetics $\Delta \mathrm{W}_{\mathrm{OK}}=\mathrm{W}_{\mathrm{OK}}-\left(\mathrm{W}_{\mathrm{OK}}\right)_{\text {ref }}$. Normalization between $\mathrm{O}$ and $\mathrm{J}(2 \mathrm{~ms})$ steps revealed $\mathrm{K}$-band, presented as variable fluorescence $\mathrm{W}_{\mathrm{OJ}}=\left(\mathrm{F}_{\mathrm{t}}-\mathrm{F}_{0}\right) /\left(\mathrm{F}_{\mathrm{J}}-\mathrm{F}_{0}\right)$ and plotted with difference kinetics $\Delta \mathrm{W}_{\mathrm{OJ}}=\mathrm{W}_{\mathrm{OJ}}-\left(\mathrm{W}_{\mathrm{OJ}}\right)_{\text {ref }}$. Values measured in control plants were used as referent value $\left(\mathrm{W}_{\mathrm{OK}}\right)_{\text {ref }}$ (Strasser et al., 2004; Yusuf et al., 2010).

\section{Biochemical Stress Parameters}

Levels of MDA and proline were determined spectrophotometrically using previously reported methods (Radić et al., 2009). Plant material for determination of MDA levels (250 mg of fresh weight of leaves and roots) was extracted in $2 \mathrm{ml}$ of potassium phosphate buffer $(50 \mathrm{mM}, \mathrm{pH} 7.0,0.1 \mathrm{mM}$ EDTA) with the addition of polyvinylpolypyrrolidone (PVPP). MDA levels in the extracts were estimated by MDA reaction with thiobarbituric acid, subtracting the absorbance at $600 \mathrm{~nm}$ from the absorbance at $532 \mathrm{~nm}$, and using an extinction coefficient of $155 \mathrm{mM}^{-1} \mathrm{~cm}^{-1}$.

Proline was extracted from $100 \mathrm{mg}$ samples (FW) in $1.5 \mathrm{ml}$ of $3 \%$ sulfosalicylic acid and determined spectrophotometrically at $520 \mathrm{~nm}$ using ninhydrin. Absorbance values were adjusted using a calibration curve constructed with L-proline as a standard and the results were expressed in nmol proline per $\mathrm{g}$ FW.

A Specord 40 spectrophotometer (Analytik Jena, Jena, Germany) was used for all absorbance measurements, with four replicates per assay. 


\section{Contents of Sodium and Potassium Ions}

Contents of sodium and potassium ions in roots and leaves of the Brassica crops were measured by high-resolution inductively coupled plasma mass spectrometry, using a Thermo Fisher Scientific HRICP-MS Element 2 instrument (Thermo Fisher Scientific, Bremen, Germany) equipped with an ESI-a SC-2 DX FAST autosampler (Elemental Scientific, United States) using indium as an internal standard. Typical instrumental conditions and measurement parameters used throughout the work have been previously reported (Fiket et al., 2016). Before analysis, powdered lyophilized tissue samples were subjected to microwave-assisted acidic digestion in $\mathrm{HNO}_{3} / \mathrm{HF}(60: 1, \mathrm{v} / \mathrm{v})$ using a Multiwave 3000 (Anton Paar, Graz, Austria) at 1400 W.

\section{Hormonal Profiling}

\section{Stress-Related Hormones}

The stress-related phytohormones, JAs (jasmonic acid, JA, and jasmonoyl-L-isoleucine, JA-Ile) and ABA were determined as previously described (Floková et al., 2014) with minor modifications. Briefly, lyophilized samples $(5 \mathrm{mg}$ dry weight, DW) were homogenized with a MM 301 vibration mill (Retsch GmbH, Haan, Germany), extracted in $1 \mathrm{~mL} 50 \mathrm{mM}$ sodium phosphate buffer ( $\mathrm{pH}$ 7.0) containing $1 \%$ sodium diethyldithiocarbamate and stable isotope-labeled internal standards $\left(10 \mathrm{pmol}\left[{ }^{2} \mathrm{H}_{6}\right] \mathrm{JA}, 10 \mathrm{pmol}\left[{ }^{2} \mathrm{H}_{6}\right] \mathrm{ABA}\right.$ and $0.1 \mathrm{pmol}$ $\left[{ }^{2} \mathrm{H}_{2}\right] J A-I l e ;$ OlchemIm, Olomouc, Czechia) then alkalized by adding $1 \mathrm{~mL}$ of $5 \% \mathrm{NH}_{4} \mathrm{OH} / \mathrm{H}_{2} \mathrm{O}(v / v)$. The resulting solution was purified by passage through a mixed-mode anion exchange column (Oasis ${ }^{\circledR}$ MAX column, 1 cc/30 mg, Waters, Milford, MA, United States) conditioned with $100 \% \mathrm{MeOH}$ and equilibrated with $\mathrm{H}_{2} \mathrm{O}$ and $5 \% \mathrm{NH}_{4} \mathrm{OH}$ ( $1 \mathrm{ml}$ of each solution). After sample loading, the column was washed with $2 \mathrm{~mL} 5 \% \mathrm{NH}_{4} \mathrm{OH}$ followed by $2 \mathrm{~mL} 100 \% \mathrm{MeOH}$, then the acidic phytohormones were eluted using $2 \mathrm{~mL} 2 \% \mathrm{HCOOH}$ in $100 \% \mathrm{MeOH}(v / v)$. The samples were evaporated to dryness under a stream of nitrogen and stored in a freezer at $-20^{\circ} \mathrm{C}$ until analysis.

\section{Brassinosteroids}

Samples' BR contents were analyzed as previously described (Oklestkova et al., 2017) with a few modifications. Briefly, lyophilized samples (40 $\mathrm{mg} \mathrm{DW}$ ) were homogenized to a fine consistency using $3 \mathrm{~mm}$ zirconium oxide beads and an MM 301 vibration mill at a frequency of $30 \mathrm{~Hz}$ for 3 min (Retsch, Haan, Germany). The samples were then extracted overnight with stirring at $4^{\circ} \mathrm{C}$ using a benchtop laboratory rotator (Stuart SB3; Bibby Scientific, Cole-Parmer, Staffordshire, United Kingdom) after adding $1 \mathrm{~mL}$ of icecold $60 \%$ acetonitrile and 30 pmol of $\left[{ }^{2} \mathrm{H}_{3}\right]$ brassinolide (BL), $\left[{ }^{2} \mathrm{H}_{3}\right]$ castasterone (CS), $\left[{ }^{2} \mathrm{H}_{3}\right]$ typhasterol (TY), $\left[{ }^{2} \mathrm{H}_{3}\right] 24-e p i \mathrm{BL}$, $\left[{ }^{2} \mathrm{H}_{3}\right] 24$-epiCS, $\left[{ }^{2} \mathrm{H}_{3}\right] 28$-norBL, and $\left[{ }^{2} \mathrm{H}_{3}\right] 28$-norCS (OlchemIm, Olomouc, Czech Republic) as internal standards. The samples were then centrifuged, purified using DPA-6S SPE columns (Supelco, Bellefonte, PA, USA) and evaporated to dryness in vacuo. They were then dissolved in $75 \mu \mathrm{l} 100 \% \mathrm{MeOH}$ with sonication, made up to $1 \mathrm{ml}$ with PBS buffer ( $\mathrm{pH}$ 7.2) then loaded on an immunoaffinity column (IAC) coated with anti-BR monoclonal antibodies. After washing the IAC with
$9 \mathrm{~mL} \mathrm{H}_{2} \mathrm{O}$, BRs were eluted using $3 \mathrm{~mL}$ ice-cold $\mathrm{MeOH}$ $\left(-20^{\circ} \mathrm{C}\right)$, evaporated in vacuo using a CentriVap ${ }^{\circledR}$ acid-resistant benchtop concentrator (Labconco Corp., MO, USA) and stored at $-20^{\circ} \mathrm{C}$ until analysis.

\section{UHPLC-MS/MS Analysis}

For ultra-high performance liquid chromatography-tandem mass spectrometry (UHPLC-MS/MS) analysis, all samples were dissolved in $40 \mu \mathrm{L}$ of the mobile phase and analyzed using an Acquity UPLC System (Waters, Milford, MA, USA) coupled to a Xevo ${ }^{\mathrm{TM}}$ TQ-S MS triple quadrupole mass spectrometer (Waters, MS Technologies, Manchester, United Kingdom). Stable isotope-labeled internal standards were used as references and concentrations of analytes were quantified by the isotope dilution method. Previously published instrument settings were used for profiling stress-related phytohormones (Floková et al., 2014) and BRs (Oklestkova et al., 2017). Four independent replicate analyses were performed for each hormone group if not stated otherwise.

\section{Statistical Analysis}

Between-treatment differences in measured variables of each of the Brassica crops were evaluated using factorial analysis of variance (ANOVA) followed by the post hoc Tukey Honest Significant Difference (HSD) test. Differences were considered significant if $p<0.05$. To minimize bias in comparisons of the varieties, which differed in salinity tolerance, all data were normalized to control values. Data presented in the text, figures, and tables are means \pm standard deviation of four replicates $(n=4)$ for biochemical markers and phytohormones, and means \pm standard deviation of 18 replicates $(n=18)$ for fluorescence measurements.

\section{Principal Component Analysis}

Correlations among the measured physiological, biochemical, and hormonal parameters, treatments and responses of the Brassica crops were explored by PCA. PCA was performed using the correlation matrix of the average values of traits after standardization (autoscaling). Linear correlations among variables were determined by Pearson coefficients $(p<0.05)$. XLSTAT software (ver. 2017.01.40777) implemented in Microsoft Office Excel 2010 was used for all statistical procedures.

\section{RESULTS}

\section{Salinity Tolerance Evaluation by Root-Growth Bioassay}

The inhibition of root-growth during exposure to $\mathrm{NaCl}$ at 50-200 mM for $24 \mathrm{~h}$ was used as a quick, convenient bioassay to evaluate the salinity tolerance of the selected brassicas (Figure 1). As shown in Figure 1, the treatments caused dose-dependent root-growth inhibition in all three varieties, but most strongly in Chinese cabbage. Root-growth inhibition rates were similar in white cabbage and kale. Seedlings biomass production upon prolonged salinity stress (up to 7 days) showed statistically significant inhibition in Chinese cabbage and white cabbage 


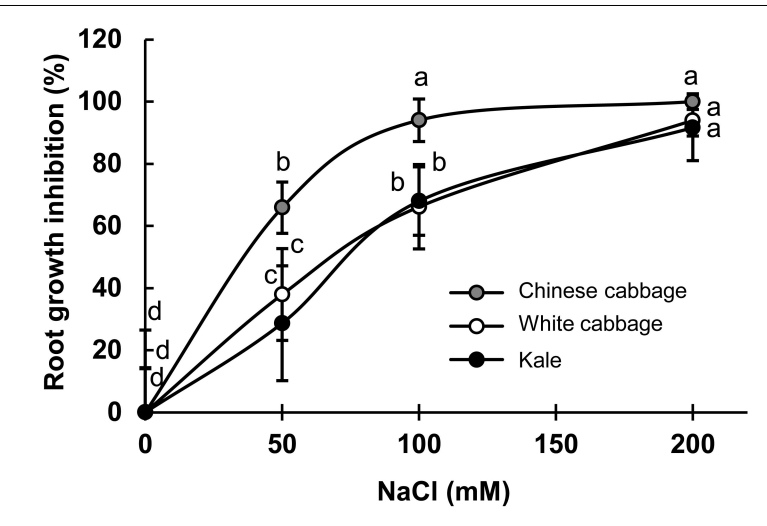

FIGURE 1 | Dose-dependent root-growth inhibition of Chinese cabbage (B. rapa), white cabbage (B. oleracea var. capitata), and kale (B. oleracea var acephala) exposed to indicated $\mathrm{NaCl}$ concentrations (0-200 mM), relative to salt-free controls (\%). Presented data are means $\pm \mathrm{SD}, n=30$. Points labeled with different letters differ significantly at $p<0.05$.

at higher salt concentrations (100 and $200 \mathrm{mM} \mathrm{NaCl}$ ), while there is no significant inhibition in biomass production in kale (Supplementary Figure S1 in the Supplementary File).

\section{Salinity Effects on Photosynthetic Performance}

To acquire information about the selected brassicas' photosynthetic performance, we measured fluorescence transients of hydroponically grown plants exposed to 50,100, or $200 \mathrm{mM}$ $\mathrm{NaCl}$ (Figures 2D-F). Normalized OJIP transients, indicating differences between control and stressed plants in PSII and PSI functionality, demonstrated that the fluorescence intensity at defined transient steps successively increased with increases in $\mathrm{NaCl}$ concentration in all three brassicas. Spider plots presenting normalized values of $\mathrm{NaCl}$-treated plants relative to the controls are shown in Figures 2A-C. The plots show clear between-taxa differences in total photosynthetic performance index, $\mathrm{PI}_{\text {total }}$, a sensitive parameter reflecting the functional activity of PSI, PSI, and intersystem electron transport chain. The $\mathrm{PI}_{\text {total }}$ of Chinese cabbage decreased 26.6, 47, and 66.6\% after exposure to 50,100 , and $200 \mathrm{NaCl}$, respectively, while decreases were only detected after exposure to 100 and $200 \mathrm{mM} \mathrm{NaCl}$ in white cabbage (23.8 and $46.2 \%$, respectively) and kale (26.7 and $41.9 \%$, respectively). The density of reaction centers (RCs) per unit chlorophyll $a, \mathrm{RC} / \mathrm{ABS}$, in Chinese cabbage decreased $8 \%$ at the highest $\mathrm{NaCl}$ concentration. In contrast, 100 and $200 \mathrm{mM} \mathrm{NaCl}$ induced significant increases in $\mathrm{RC} / \mathrm{ABS}$ in white cabbage (8.4 and $11.5 \%$, respectively) and kale (8.1 and $8.9 \%$, respectively). Flux ratio trapping per dissipation, $\mathrm{TR}_{0} / \mathrm{DI}_{0}$, and electron transport further than $\mathrm{Q}_{\mathrm{A}}, \mathrm{ET}_{0} /\left(\mathrm{TR}_{0}-\mathrm{ET}_{0}\right)$, significantly declined in Chinese cabbage exposed to 100 and $200 \mathrm{mM} \mathrm{NaCl}$ (by 8.8 and 14.9\%, respectively). In white cabbage and kale, these parameters decreased significantly only at the highest $\mathrm{NaCl}$ concentration, relative to controls (by 12.2 and $7.9 \%$, respectively).
The probability of end electron acceptor reduction, $\mathrm{RE}_{0} /$ $\left(\mathrm{ET}_{0}-\mathrm{RE}_{0}\right)$, decreased in Chinese cabbage by 20.6, 33.3, and $48.6 \%$ after exposure to 50, 100 and $200 \mathrm{NaCl}$, respectively. However, this parameter decreased only after exposure to 100 and $200 \mathrm{mM} \mathrm{NaCl}$, relative to controls, in white cabbage (by 25.5 and $39.5 \%$, respectively) and kale (by 30.5 and $38.9 \%$, respectively).

Fluorescence intensity at $50 \mathrm{~s}\left(\mathrm{~F}_{0}\right)$ was not affected in any cultivar by any of the salt treatments. The maximum fluorescence intensity $\left(\mathrm{F}_{\mathrm{m}}\right)$ was significantly decreased by exposure to 100 and $200 \mathrm{mM} \mathrm{NaCl}$ in Chinese cabbage (by 5.9 and $12.4 \%$, respectively), while in white cabbage and kale it only significantly decreased at $200 \mathrm{mM}$ (by 6.4 and 6.5\%, respectively) relative to controls. Similarly, the maximum quantum yield of primary photochemistry, $\mathrm{TR}_{0} / \mathrm{ABS}$, significantly decreased in Chinese cabbage at 100 and $200 \mathrm{mM} \mathrm{NaCl}$ relative to controls (by 1.7 and $3.1 \%$, respectively), while in white cabbage and kale it decreased only at the highest $\mathrm{NaCl}$ concentration (by 1.5 and $1.2 \%$, respectively).

Variable fluorescence at $150 \mu \mathrm{s}\left(\mathrm{V}_{\mathrm{L}}\right)$ showed no significant changes in any cultivar after exposure to salt at any concentrations relative to controls. Variable fluorescence at $300 \mu \mathrm{s}\left(\mathrm{V}_{\mathrm{K}}\right)$ significantly increased (by 5.3\%) at the highest $\mathrm{NaCl}$ concentration in Chinese cabbage, while 100 and $200 \mathrm{mM} \mathrm{NaCl}$ caused significant reductions (7.2 and 9.2\%, respectively) of this parameter in kale. There were significant increases in variable fluorescence at the $\mathrm{J}$ step $\left(\mathrm{V}_{\mathrm{J}}\right)$ in Chinese cabbage at 100 and $200 \mathrm{mM} \mathrm{NaCl}$ (5.9 and $10.7 \%$, respectively), but only at $200 \mathrm{mM}$ in white cabbage and kale ( 9.1 and $5.8 \%$, respectively). Similarly, variable fluorescence at $30 \mathrm{~s}\left(\mathrm{~V}_{\mathrm{I}}\right)$ increased after exposure to 50,100 , and $200 \mathrm{mM} \mathrm{NaCl}$ in Chinese cabbage (by 5.0, 8.4, and $13.0 \%$, respectively), but only after exposure to 100 and $200 \mathrm{mM}$ $\mathrm{NaCl}$ in white cabbage (by 7.0 and $12.2 \%$, respectively) and kale (by 8.2 and $11.1 \%$, respectively).

There were clear differences in L-bands (Figures 3A-C) and $\mathrm{K}$-bands (Figures 3D-F), obtained from the normalized $\mathrm{O}-\mathrm{K}$ and O-J curves between Chinese cabbage and the two other Brassica crops. Bands for Chinese cabbage were positive and their amplitude was highest after exposure to $200 \mathrm{mM} \mathrm{NaCl}$. In contrast, both bands for white cabbage and kale were negative after exposure to $\mathrm{NaCl}$ at all concentrations, but again their amplitude was highest at $200 \mathrm{mM} \mathrm{NaCl}$.

\section{Effects of Salinity on Biochemical and Physiological Stress Parameters}

To evaluate effects of the treatments to major known biochemical salinity stress markers, the $\mathrm{Na}^{+} / \mathrm{K}^{+}$ratio, and levels of proline and MDA (Figure 4) were measured in roots and leaves of the selected Brassica crops.

Maintenance of the potassium to sodium ionic ratio and accumulation of proline are salinity defense strategies. The increase of sodium ions and decrease of potassium ions (Supplementary Table S2) resulted in higher $\mathrm{Na}^{+} / \mathrm{K}^{+}$ratio upon salinity (Figures 4 A,B). The $\mathrm{Na}^{+} / \mathrm{K}^{+}$ratio was affected more strongly in roots than in leaves, and exposure to the highest salt concentration (200 mM) resulted in 254-, 291-, and 589 -fold changes in Chinese cabbage, white cabbage, and kale 


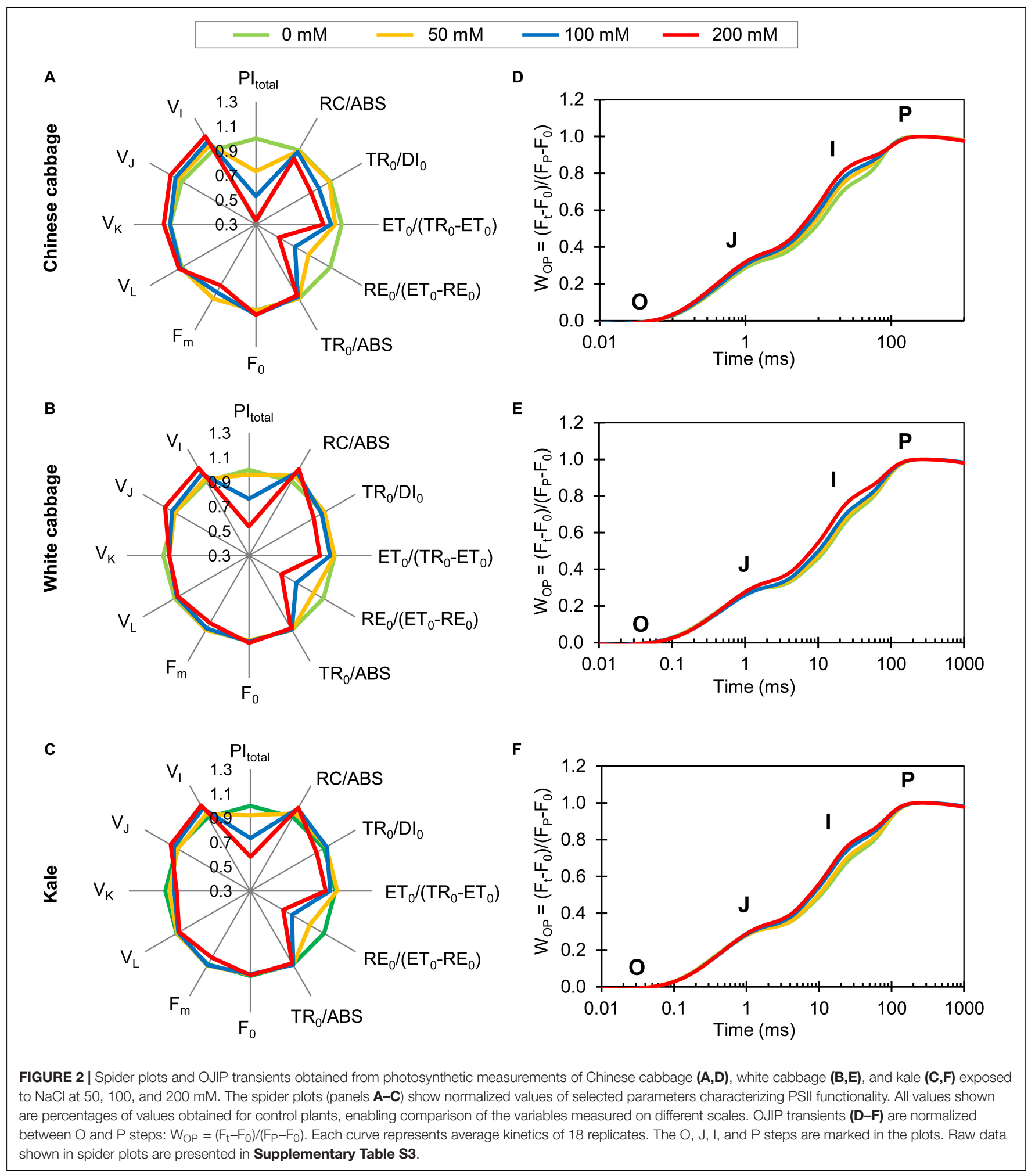

roots, respectively, relative to controls (Figure 4A). The highest difference in $\mathrm{Na}^{+} / \mathrm{K}^{+}$ratio in leaves between control and salt treatments was 43 -fold, in Chinese cabbage after exposure to $200 \mathrm{mM} \mathrm{NaCl}$ (Figure 4B), which induced ca. 10-fold increases in the $\mathrm{Na}^{+} / \mathrm{K}^{+}$ratios of the other two brassicas' leaves. The osmotic effect of $\mathrm{NaCl}$ was evaluated by monitoring changes in levels of proline (Figures 4C,D), which successively increased after exposure to 100 and $200 \mathrm{mM} \mathrm{NaCl}$ in both roots and leaves of the three crops. We detected 9.6-, 5.7-, and 8.2-fold increases in proline levels in roots of Chinese cabbage, white cabbage, and 


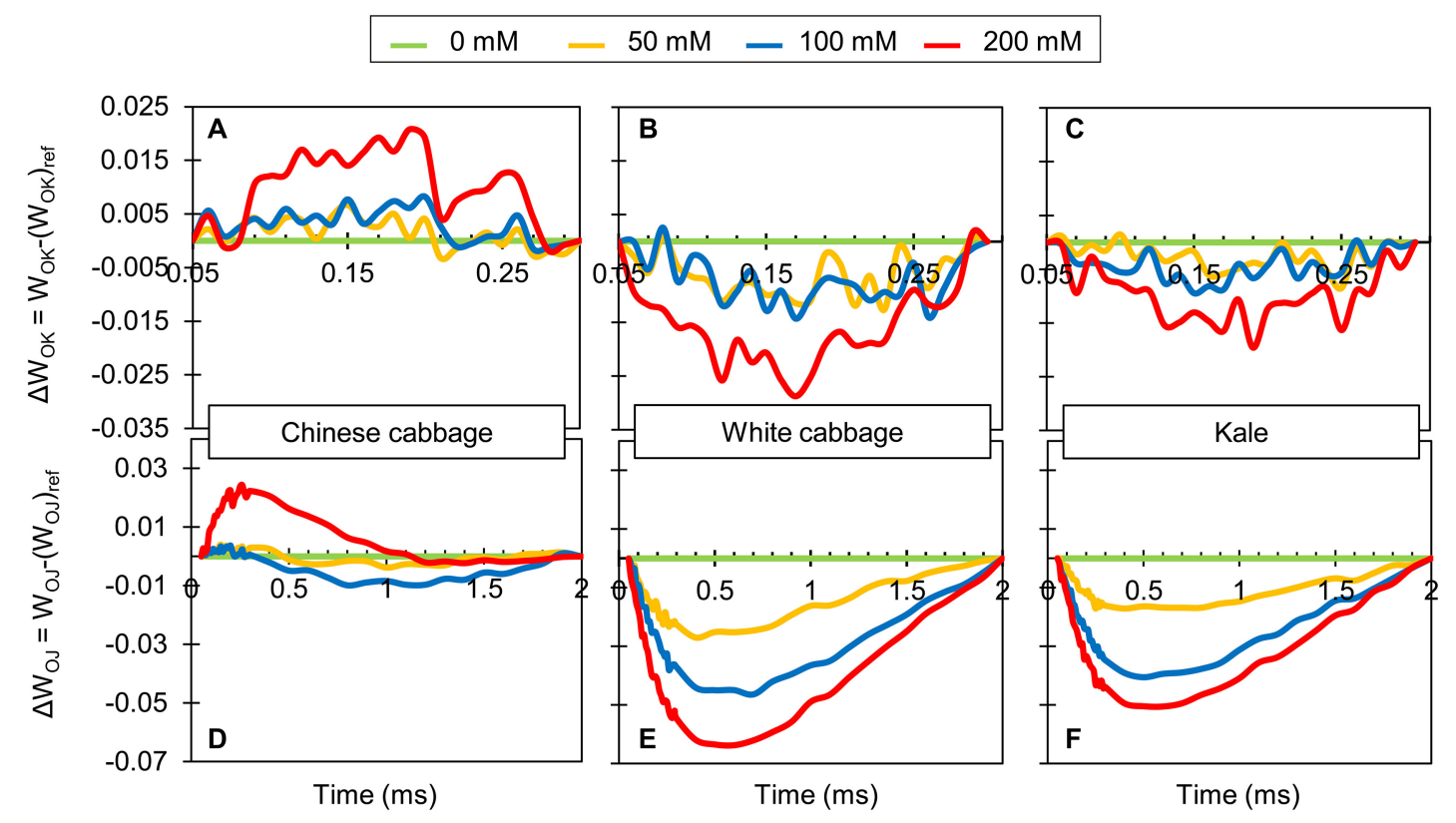

FIGURE 3 | Chlorophyll a fluorescence transient curves obtained for leaves of Chinese cabbage (A,D), white cabbage (B,E), and kale (C,F) exposed to NaCl at 50, 100, and $200 \mathrm{mM}$. Each curve represents average kinetics of 18 replicates. Average fluorescence data were normalized between $\mathrm{O}$ and $\mathrm{K}$ steps (L-band; $\mathbf{A}-\mathbf{C}$ ) and plotted as difference kinetics $\Delta \mathrm{W}_{\mathrm{OK}}=\mathrm{W}_{\mathrm{OK}}-\left(\mathrm{W}_{\mathrm{OK}}\right)_{\text {ref }}$ in the 0.05-3 ms time range. Fluorescence data normalized between $\mathrm{O}$ and $\mathrm{J}$ steps $(\mathrm{K}-\mathrm{band}$; $\mathbf{D}-\mathbf{F})$ were plotted as difference kinetics $\Delta \mathrm{W}_{\mathrm{OJ}}=\mathrm{W}_{\mathrm{OJ}}-\left(\mathrm{W}_{\mathrm{OJ}}\right)_{\text {ref }}$ in the $0.05-2 \mathrm{~ms}$ time range. $\left(\mathrm{W}_{\mathrm{OK}}\right)_{\text {ref }}$ and $\left(\mathrm{W}_{\mathrm{OJ}}\right)_{\text {ref }}$ reference values were obtained from measurements of control plants for each species.

kale, respectively, after exposure to $200 \mathrm{mM} \mathrm{NaCl}$, relative to controls (Figure 4C), and much higher increases in their leaves (15.6-, 39.7-, and 13.9-fold, respectively) (Figure 4D). To evaluate the oxidative effects of the treatments, MDA contents were measured (Figures 4E,F). The treatments did not significantly affect the MDA content in kale roots but significantly affected it in Chinese cabbage roots at all salt concentrations and white cabbage roots at higher salt concentrations (100 and $200 \mathrm{mM}$ $\mathrm{NaCl}$ ) (Figure 4E). Moreover, the two highest salt concentrations (100 and $200 \mathrm{mM}$ ) increased MDA levels in leaves of all three brassicas relative to corresponding controls (Figure 4F).

\section{Effects of Salinity on Stress Hormones}

Changes in stress-related hormones (ABA, JA, and JA-Ile) induced by the treatments are shown in Figure 5. Exposure to 100 and $200 \mathrm{mM} \mathrm{NaCl}$ caused significant increases in ABA levels in roots and leaves of all three brassicas (Figures 5A,B). The strongest increase in roots (2.85-fold relative to controls) was induced by exposure to $100 \mathrm{mM} \mathrm{NaCl}$ in roots of kale. However, the highest salinity $(200 \mathrm{mM} \mathrm{NaCl})$ decreased ABA levels in roots of Chinese cabbage (to 62\% of control levels), although it increased them (approximately twofolds relative to controls) in white cabbage and kale roots. In leaves, the highest increase in ABA levels (25.5-fold) was also induced by $100 \mathrm{mM}$ $\mathrm{NaCl}$ in Chinese cabbage (Figure 5B). The $200 \mathrm{mM} \mathrm{NaCl}$ treatment resulted in a smaller increase in ABA levels in Chinese cabbage, but similar and further increases in levels relative to those induced by $100 \mathrm{mM} \mathrm{NaCl}$ in leaves of white cabbage and kale, respectively. Levels of JAs (JA and JA-Ile) in roots and leaves (Figures 5C-F) showed similar responses to the salt stress treatments in all three crops. In mild stress conditions (50 mM NaCl) JA and JA-Ile (Figures 5D,F) remained at control levels in leaves of Chinese and white cabbage while levels of both hormones were significantly lower in kale. In root tissue, reductions in JA and JA-Ile contents (Figures $5 \mathrm{C}, \mathbf{E}$ ) were more pronounced in Chinese cabbage than in the other crops at $50 \mathrm{mM}$ $\mathrm{NaCl}$. Higher salinity resulted in significant decreases in levels of both hormones in roots and leaves of all three brassicas.

\section{Effects of Salinity on Brassinosteroids}

Changes in levels of BRs in the brassicas induced by the treatments are presented in Figure 6. In both roots and leaves, only three BRs (TY, CS, and BL) were detected. Reductions in levels of the precursor TY in roots and leaves (Figures 6A,B) were accompanied by increases in BL (Figures 6E,F) in both organs of Chinese cabbage exposed to $\mathrm{NaCl}$ at all concentrations, relative to controls. In contrast, TY, CS, and $\mathrm{BL}$ levels were moderately reduced in leaves and not affected in roots of white cabbage. The three stress treatments induced significant increases in levels of TY, CS, and BL in roots of kale (except in CS levels at $100 \mathrm{mM} \mathrm{NaCl}$ ), but either no significant changes or reductions in kale leaves.

\section{Principal Component Analysis (PCA)}

To investigate correlations among the brassicas in terms of the measured stress-related parameters, the data were subjected to PCA based on a matrix of Pearson correlation coefficients $(p<0.05)$. Average values of measured traits were standardized 

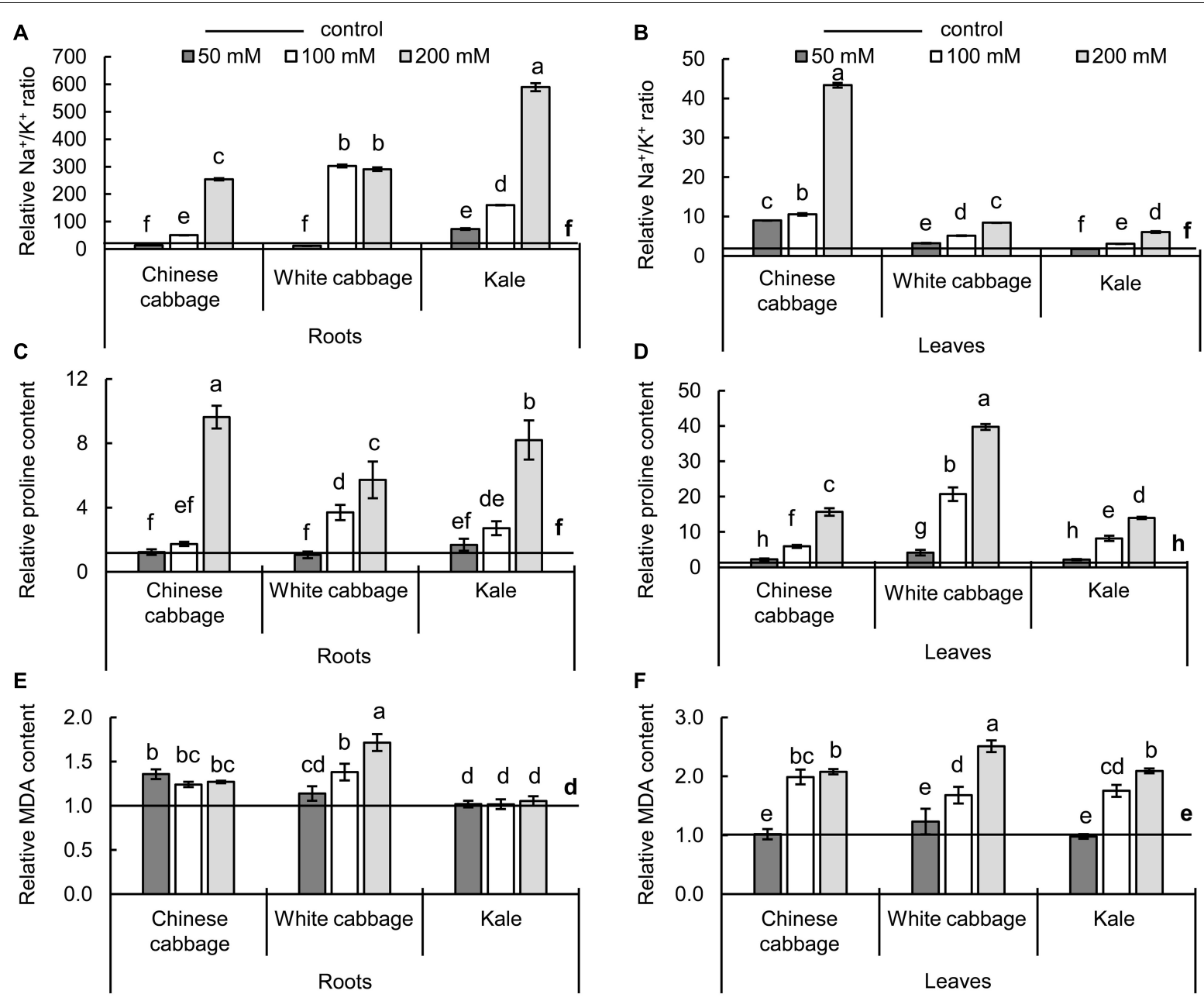

FIGURE 4 | $\mathrm{Na}^{+} / \mathrm{K}^{+}$ratios (A,B), and contents of proline (C,D), and malondialdehyde (MDA) (E,F) of the three Brassica crops in roots (left panels) and leaves (right panels) after exposure to 50,100 , and $200 \mathrm{mM} \mathrm{NaCl}$, relative to $\mathrm{NaCl}$-free controls. Normalized values of salt treatments presented as means $\pm \mathrm{SD}, n=4$. Points labeled with different letters differ significantly at $p<0.05$. Raw data are presented in Supplementary Table S2.

prior to analysis by autoscaling. The resulting correlation matrix, eigenvalues, factor loadings and factor scores are presented in Supplementary Tables S6-S20. Positions of the brassicas and relations among the measured parameters under the salinity treatments, in roots and leaves are shown in PCA biplots in Figures 7A,B, respectively. The first two Principal Components, F1 and F2, explained 61.24 and $65.70 \%$ of the cumulative variability of measured traits in the roots and leaves, respectively. Detailed PCA of correlations of photosynthetic parameters with the cultivars and treatments is presented in Supplementary Figure S2 in the Supplementary File and Supplementary Tables S16-S20. The first two Principal Components explained $79.85 \%$ of the cumulative variability of photosynthetic traits in leaves.

The separation of the cultivars, particularly Chinese cabbage, in the root biplot (Figure 7A) clearly shows that their salinity responses differ. Kale and white cabbage treatments were grouped close to their controls in the left quadrants, while Chinese cabbage treatments were positioned far away from the corresponding control. The PCA plot also shows relations of the measured parameters in the brassicas' responses (factor loadings are presented in Supplementary Tables S8, S13 for roots and leaves, respectively). The phytohormones $\mathrm{BL}$ and $\mathrm{ABA}$, and stress marker MDA are positioned close to 50 and $100 \mathrm{mM}$ $\mathrm{NaCl}$-treated Chinese cabbage roots, while proline is grouped together with 100 and $200 \mathrm{mM} \mathrm{NaCl}$-treated white cabbage roots and Chinese cabbage at $200 \mathrm{mM} \mathrm{NaCl}$, indicating that they are the main response parameters to these treatments. Parameters positioned in the same quadrant as kale roots and white cabbage under control and $50 \mathrm{mM} \mathrm{NaCl}$ treatments are TY and $\mathrm{Na}^{+} / \mathrm{K}^{+}$ratio.

In the leaf biplot (Figure 7B), cultivars exposed to the control and mild stress $(50 \mathrm{mM} \mathrm{NaCl})$ treatments are grouped together on the left side of the plot, and the severe salinity treatments shifted them to the right. Like the pattern in the root biplot, Chinese cabbage leaves were positioned far from kale leaves, and white cabbage leaves exposed to the salinity treatments were in intermediate positions, indicating differences in their salinity 

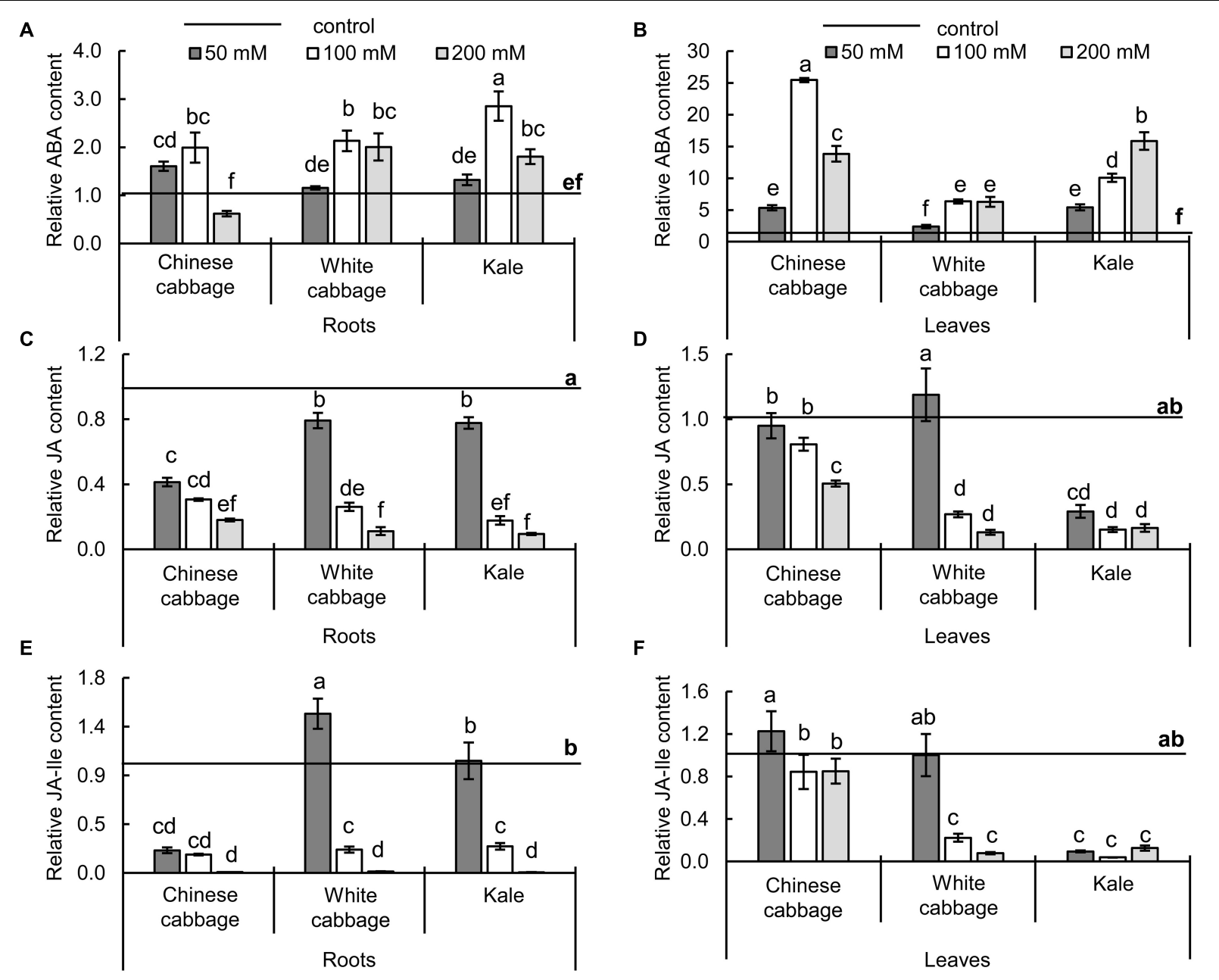

FIGURE 5 | Levels of stress-related hormones - abscisic acid (ABA, A,B), jasmonic acid (JA, C,D), and jasmonoyl-L-isoleucine (JA-Ile, E,F) - in roots (left panels) and leaves (right panels) of Chinese cabbage, white cabbage, and kale after 24 h exposure to 50, 100, and $200 \mathrm{mM} \mathrm{NaCl}$, relative to corresponding controls. Normalized values presented as means $\pm \mathrm{SD}, n=4$. Points labeled with different letters differ significantly at $p<0.05$. Raw data are presented in Supplementary Table S4.

responses and hence sensitivity to salt stress. The parameters positioned closest to Chinese cabbage exposed to severe salinity are the phytohormones $\mathrm{ABA}$ and $\mathrm{BL}$, together with $\mathrm{Na}^{+} / \mathrm{K}^{+}$ ratio, while proline, and MDA are positioned closer to the other two Brassica varieties.

There were also significant correlations between phytohormones, biochemical, and selected photosynthetic parameters $\left(\mathrm{PI}_{\text {total }}\right.$ and $\left.\mathrm{TR}_{0} / \mathrm{ABS}\right)$ that reflect the overall efficiency of photosynthesis in leaves (Supplementary Table S11). These photosynthetic parameters were negatively correlated with the $\mathrm{Na}^{+} / \mathrm{K}^{+}$ratio, proline and MDA, as well as $\mathrm{ABA}$.

Based on photosynthetic parameters, B. oleracea cultivars (controls and salinity-treated) grouped close together and far from Chinese cabbage (Supplementary Figure S2 in the Supplementary File). $\mathrm{PI}_{\text {total }}$ was positively correlated with its constituents: $\mathrm{TR}_{0} / \mathrm{DI}_{0}, \mathrm{ET}_{0} /\left(\mathrm{TR}_{0}-\mathrm{ET}_{0}\right), \mathrm{RE}_{0} /\left(\mathrm{ET}_{0}-\mathrm{RE}_{0}\right)$, and $\mathrm{TR}_{0} / \mathrm{ABS}$, but negatively correlated with $\mathrm{RC} / \mathrm{ABS}$. It was also positively correlated with $F_{m}$ but negatively correlated with $V_{J}$ and $\mathrm{V}_{\mathrm{I}} \cdot \mathrm{PI}_{\text {total }}$ and its constituents were grouped close to control and mild salinity-treated $B$. oleracea varieties (white cabbage and kale), while the $\mathrm{V}_{\mathrm{J}}, \mathrm{V}_{\mathrm{L}}$, and $\mathrm{V}_{\mathrm{I}}$ parameters were positioned closer to Chinese cabbage.

\section{DISCUSSION}

Soil salinization is a major agricultural problem, which impairs crops' growth, yields, and quality. Soils with electrical conductivity (EC) of $>4 \mathrm{dS} / \mathrm{m}$ are characterized as saline. However, under some environmental conditions, soil EC values can exceed $20 \mathrm{dS} / \mathrm{m}$ (corresponding to $200 \mathrm{mM} \mathrm{NaCl}$ ) (Shannon and Grieve, 1999; Zhang et al., 2014). Thus, there are urgent needs to characterize crops' salinity responses and the mechanisms involved in salinity tolerance. To aid such efforts we have examined, in detailed responses of selected brassicas to short-term salinity: Chinese cabbage ( $B$. rapa), white cabbage ( $B$. oleracea var. capitata) and kale (B. oleracea var. acephala). All three brassicas were grown in a hydroponic 


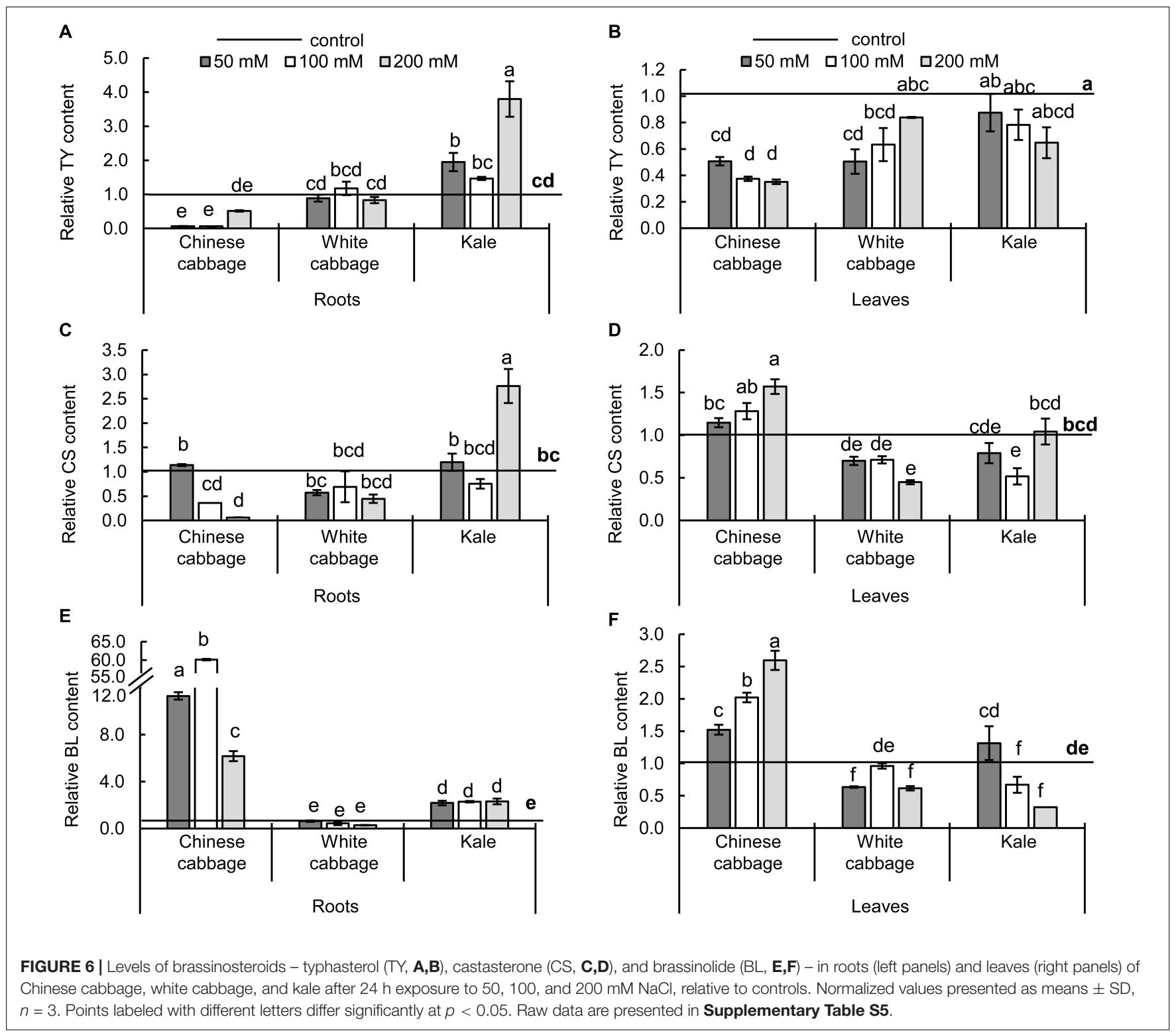

system until they reached the four fully developed leaf-stage, at which they are frequently transferred into fields in conventional cultivation systems and thus exposed to different environmental conditions. The selected salt concentrations (50, 100, and $200 \mathrm{mM} \mathrm{NaCl}$ ) correspond to concentrations in naturally occurring saline soils. Diverse physiological, biochemical, and hormonal parameters were measured to gain insights into the brassicas' responses to short-term salinity and correlations between their responses and tolerance.

\section{Salinity Tolerance and Photosynthetic Performance of the Selected Brassicas}

An earlier study on Brassica crops identified root-growth inhibition as a significant biomarker of salt sensitivity (Zhang et al., 2014). Thus, we used a simple root-growth bioassay to characterize the selected cultivars' salt sensitivity and found that Chinese cabbage was the most sensitive, while kale and white cabbage were more tolerant under the applied experimental conditions. These results are consistent with previous findings that cabbages (including $B$. oleracea var. capitata) have a salinity threshold of $180 \mathrm{mM} \mathrm{NaCl}$, kales (such as B. oleracea var. acephala) can grow after exposure to 230-550 mM NaCl following re-watering (Shannon and Grieve, 1999), while many B. rapa sub-species have been described as salt-sensitive (Jan et al., 2016). As a component of salinity stress is osmotic stress, the results are also consistent with our recently published finding of a corresponding pattern of tolerance to drought conditions (Pavlović et al., 2018b).

Photosynthesis, and hence crops' growth and productivity can be inhibited by salinity, to degrees that depend on the crops' tolerance. Therefore, we tested the influence of salinity on the 
A $\quad$ Biplot (axes F1 and F2: $61.24 \%$ )

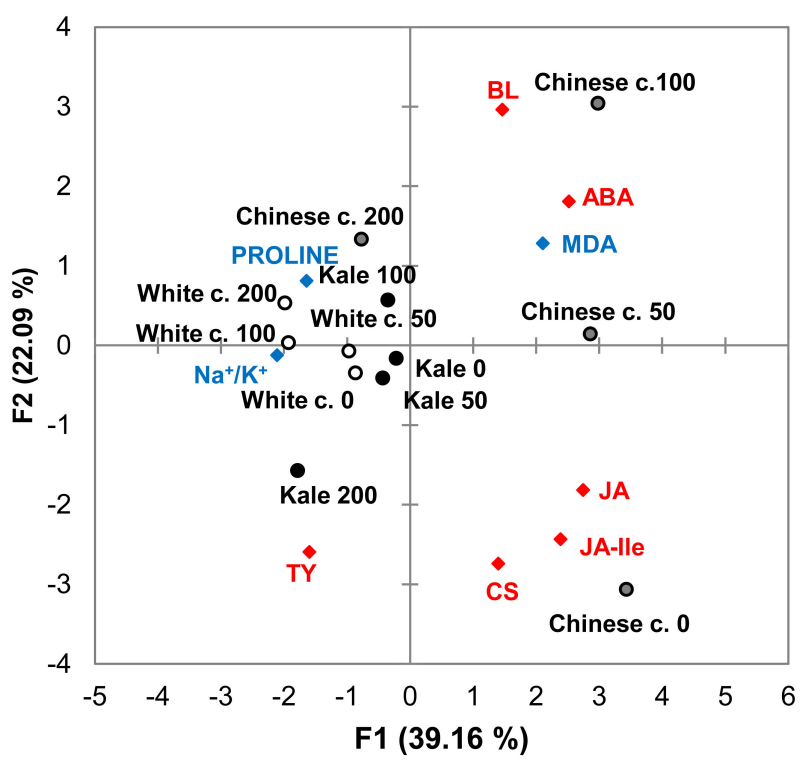

B

Biplot (axes F1 and F2: $65.70 \%$ )

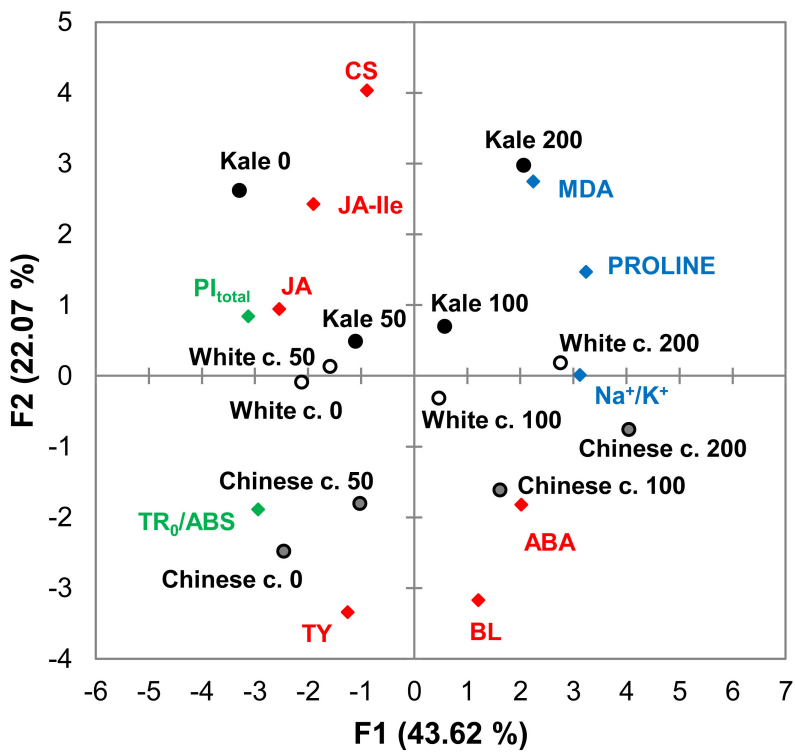

FIGURE 7 | Results of two-dimensional principal component analysis (2D-PCA) of photosynthetic parameters, biochemical markers and phytohormone levels in roots (A) and leaves (B) of Chinese cabbage (Chinese c.), white cabbage (White c.), and kale (Kale) in roots (A) and leaves (B) after 24 h exposure to 0 (control), 50 , 100, and $200 \mathrm{mM} \mathrm{NaCl}$. Green, blue, and red symbols indicate positions in the score plots of the photosynthetic markers (Figure 2), biochemical parameters (Figure 4), and phytohormones (Figures 5, 6), respectively. Round symbols indicate positions of the species' positions following each of the treatments. The correlation matrix used, eigenvalues, factor loadings and factor scores are given in Supplementary Tables S6-S15.

three brassicas' photosynthetic performance by measuring their fast chlorophyll $a$ fluorescence kinetics and determining several photosynthetic parameters. It is well known that OJIP kinetics, which reflects the redox state of $\mathrm{Q}_{\mathrm{A}}$ and $\mathrm{Q}_{\mathrm{B}}$, are extremely sensitive to salt stress (Mehta et al., 2010; Dąbrowski et al., 2016; Duarte et al., 2017). The O-J phase is a light-dependent phase of OJIP kinetics that reflects reduction of the acceptor side of PSII (Schansker et al., 2014) and provides information on antenna size and connectivity between PSII RCs. Therefore, the significantly higher increase in variable fluorescence at the J step $\left(\mathrm{V}_{\mathrm{J}}\right)$ observed in Chinese cabbage in response to salinity stress than in the other two varieties can be attributed to a stronger decrease in re-oxidation of $\mathrm{Q}_{\mathrm{A}}$. Between the $\mathrm{O}$ and $\mathrm{J}$ steps, two additional steps can be distinguished, designated the L- and K-bands (Yusuf et al., 2010). Positive L-bands obtained for salt-stressed Chinese cabbage, relative to controls (Figure 3A), indicate that its connectivity and system stability were impaired more than in the other two brassicas, for which negative L-bands were obtained. In addition, positive K-bands were obtained for salt-stressed Chinese cabbage (Figure 3D), presumably due to impaired electron flow between OEC and the acceptor side of the $\mathrm{RC}$, while negative $\mathrm{K}$-bands were obtained for salt-stressed white cabbage and kale (Yusuf et al., 2010; Chen et al., 2016). Negative K-bands have been recognized as signs of tolerance to stress conditions (Krüger et al., 2014; Żurek et al., 2014; Begović et al., 2016), indicating that PSII antennae are functionally intact (Venkatesh et al., 2012). Further, the J-I phase reflects a partial reduction of the intersystem electron carriers, while the I-P phase reflects reduction of the acceptor side of PSI (Yusuf et al.,
2010; Schansker et al., 2014). The increase in $\mathrm{V}_{\text {I }}$ induced by all salinity treatments in Chinese cabbage (Figure 2A) is attributable to faster accumulation of reduced $\mathrm{Q}_{\mathrm{A}}$ and $\mathrm{Q}_{\mathrm{B}}$-non-reducing PSII centers that cannot transfer electrons further along the electron transport chain (Tomek et al., 2001), suggesting that even the mildest salt stress partially inactivated its PSII centers. In contrast, indications of restricted electron transport between $\mathrm{Q}_{\mathrm{A}}$ and $\mathrm{Q}_{\mathrm{B}}$ (increases in $\mathrm{V}_{\mathrm{I}}$ ) in white cabbage and kale were only detected following exposure to higher $\mathrm{NaCl}$ concentrations (Figures 2B,C). Furthermore, salinity exposure decreased the photosynthetic system's ability to convert excitation energy to electron transport beyond $\mathrm{Q}_{\mathrm{A}}$. This is consistent with a recent demonstration that increases in $\mathrm{V}_{\mathrm{I}}$ are due to failure of PSI to oxidize reduced plastoquinone (Goltsev et al., 2016).

Exposure to salt stress did not induce changes in the $\mathrm{F}_{0}$ parameter in any Brassica, while the $\mathrm{F}_{\mathrm{m}}$ parameter decreased more strongly in Chinese cabbage than in the others (Figure 2) suggesting inhibition of electron flow through PSII. Reductions in the maximum yield of PSII primary photochemistry, $\mathrm{TR}_{0} / \mathrm{ABS}$ (Figures 3A-C) was obtained in all three Brassica cultivars, indicating impairment of PSII photochemical efficiency. This is supported by a recent report of similar changes in $\mathrm{F}_{0}, \mathrm{~F}_{\mathrm{m}}$ and $\mathrm{TR}_{0} / \mathrm{ABS}$ parameters in two perennial ryegrasses exposed to salt stress (Dąbrowski et al., 2016).

The most sensitive parameter of the JIP-test is the total photosynthetic performance index, $\mathrm{PI}_{\text {total }}$ (Figures 2A-C), which indicates the overall functional activity of both photosystems, PSII and PSI, as well as the intersystem electron transport chain (Yusuf et al., 2010; Krüger et al., 2014; Dạbrowski 
et al., 2016; Goltsev et al., 2016; Kalaji et al., 2017). This multiparametric expression reflects the overall efficiency of light energy absorption ( $\mathrm{RC} / \mathrm{ABS}$ ), quantum yield of excitation energy trapping $\left(\mathrm{TR}_{0} / \mathrm{DI}_{0}\right)$, probability of a trapped exciton moving an electron further along the electron transport chain than $\mathrm{Q}_{\mathrm{A}}\left[\mathrm{ET}_{0} /\left(\mathrm{TR}_{0}-\mathrm{ET}_{0}\right)\right]$ and the probability of PSI reducing its end acceptors $\left[\mathrm{RE}_{0} /\left(\mathrm{ET}_{0}-\mathrm{RE}_{0}\right)\right]$ (Yusuf et al., 2010; Krüger et al., 2014). $\mathrm{PI}_{\text {total }}$ declined in all three Brassica crops exposed to salinity (Figures 2A-C), but most strongly in Chinese cabbage. The most sensitive $\mathrm{PI}_{\text {total }}$ component to the salinity treatments was the $\mathrm{RE}_{0} /\left(\mathrm{ET}_{0}-\mathrm{RE}_{0}\right)$ parameter, reflecting the efficiency of processes involving PSI and its ability to reduce its end acceptors. In addition, reductions in $\mathrm{TR}_{0} / \mathrm{DI}_{0}$ and $\mathrm{ET}_{0} /\left(\mathrm{TR}_{0}-\mathrm{ET}_{0}\right)$ were observed in all three brassicas at the highest $\mathrm{NaCl}$ concentration, and in Chinese cabbage reductions also occurred at $100 \mathrm{mM} \mathrm{NaCl}$. This suggests that the higher $\mathrm{NaCl}$ concentrations caused structural damage to thylakoids, thereby reducing trapping of excitation energy and its conversion to electron transport. Similarly, Dąbrowski et al. (2016) reported that diminution of PSII activity and impairment of PSI function significantly decreased the total performance index in ryegrass, and Oukarroum et al. (2015) detected salt-induced inhibition of both PSII and PSI electron transport activities in duckweed. In addition, Mehta et al. (2010) suggested that salt stress decreased efficient electron transport further than the primary acceptor, and it can significantly decrease values of all parameters related to electron transport in tomato leaves (Zushi and Matsuzoe, 2017).

\section{Salt Stress-Related Biochemical Parameters in the Selected Brassicas}

An important component of plants' salt tolerance is the maintenance of an appropriate cytosolic $\mathrm{Na}^{+} / \mathrm{K}^{+}$ratio, and the tolerance of Brassica genotypes reportedly correlates inversely with $\mathrm{Na}^{+} / \mathrm{K}^{+}$ratios in their roots, steam, and leaves when exposed to salinity. Salt tolerance is also reportedly correlated with transcription levels of genes involved in ionic homeostasis, including components of the Salt Overly Sensitive (SOS) response and vacuolar NHX1 $\mathrm{Na}^{+} / \mathrm{H}^{+}$antiporter responsible for pumping $\mathrm{Na}^{+}$into vacuoles from the cytoplasm (Chakraborty et al., 2012). Furthermore, efficient compartmentalization of $\mathrm{Na}^{+}$into vacuoles and regulation of $\mathrm{Na}^{+}$transport from roots to shoots is crucial for plant survival since $\mathrm{Na}^{+}$is more toxic to leaves (Almeida et al., 2017; Assaha et al., 2017). These reports are consistent with our findings that white cabbage and kale had lower $\mathrm{Na}^{+} / \mathrm{K}^{+}$ratios in their leaves than the salt-sensitive Chinese cabbage, mainly due to increases in $\mathrm{Na}^{+}$contents. Observations of lower $\mathrm{Na}^{+} / \mathrm{K}^{+}$ratios in leaves and higher ratios in roots of white cabbage and kale suggest that control of $\mathrm{Na}^{+}$ transport from roots to leaves is more efficient in these cultivars.

In addition to ionic homeostasis, osmoregulation of cell turgor is another important physiological process under salt stress. We observed a positive correlation between the $\mathrm{Na}^{+} / \mathrm{K}^{+}$ratio and proline content. Osmoregulatory accumulation of proline under saline conditions is reportedly a common response of glycophytes, including many brassicas (Kumar et al., 2009; Mittal et al., 2012; Jan et al., 2016). Higher concentrations of proline accumulated in leaves than in roots, while the $\mathrm{Na}^{+}$ levels were much higher in roots of the selected brassicas. Similar salinity responses have been recorded in tomato plants, where proline accumulation positively correlated with expression of the P5CS (proline biosynthesis) gene and accumulation of $\mathrm{Na}^{+}$in leaves, but not in roots (Almeida et al., 2014). The cited authors concluded that there is no link between proline accumulation and a plant tolerance index, suggesting that proline "is not, per se, the driving force of tolerance." Similarly, we found that kale leaves accumulated less proline than the other two, more sensitive brassicas. Some studies suggest that proline contributes to redox homeostasis, and increases in its biosynthesis help maintain functionality of the photosynthetic apparatus and induce increases in activities of antioxidant enzymes (Puniran-Hartley et al., 2014; Surender Reddy et al., 2015). However, Pearson's coefficients we obtained show a negative correlation between the $\mathrm{PI}_{\text {total }}$ photosynthetic index and proline, suggesting that proline does not play a major protective role in photosynthesis in the selected Brassica cultivars under our experimental conditions. Furthermore, increases in MDA levels (a marker of lipid peroxidation) suggest that salt stress increases ROS production in leaves of all three brassicas more than in roots. The pro-oxidant character of high endogenous proline levels (Soshinkova et al., 2013) in leaves or insufficient antioxidant machinery could potentially explain our findings.

\section{Roles of Phytohormones in Salinity Responses of the Selected Brassicas}

Early stress responses are mediated by complex crosstalk of phytohormones (including synergistic and antagonistic interactions), among which $\mathrm{ABA}$ is reportedly the main salinity messenger (Fahad et al., 2015). Links between ABA and salinity tolerance are widespread in the plant kingdom but highly dependent on genotype, developmental stage, and stress conditions. Increases in ABA in responses to salinity have been detected in sensitive genotypes of tomato (Duan et al., 2012), basil (Mancarella et al., 2016), and barley (Witzel et al., 2014). However, significant increases in ABA have also been recorded in early responses of a tolerant barley variety (Kamboj et al., 2015) and sustained responses of a tolerant tomato cultivar (Gharbi et al., 2017). According to Ellouzi et al. (2014), the halophytes Cakile maritima and Thellungiella salsuginea can accumulate ABA more efficiently than the glycophyte $A$. thaliana under extreme salinity $(400 \mathrm{mM} \mathrm{NaCl})$. These findings are consistent with our results. The moderately tolerant white cabbage and tolerant kale maintained or dose-dependently increased levels of ABA in their leaves in response to salt. In contrast, ABA levels were lower than control levels in roots of the saltsensitive Chinese cabbage at $200 \mathrm{mM} \mathrm{NaCl}$, and lower in its leaves at $200 \mathrm{mM}$ than at $100 \mathrm{mM} \mathrm{NaCl}$. Moreover, observed decreases in the photosynthetic parameter $\mathrm{PI}_{\text {total }}$, particularly in Chinese cabbage leaves, are consistent with control of transpiration in salinity responses through ABA-induced stomatal closure and associated reductions in photosynthetic rates (Ashraf and Harris, 2013). 
Furthermore, the observed accumulation of proline following exposure to salinity can be partially explained by increased levels of ABA since proline biosynthesis is regulated by an ABAdependent and an ABA-independent pathway (Strizhov et al., 1997; Verslues and Bray, 2006). Thus, the observed discrepancy between proline accumulation and changes in ABA levels implies that the selected brassicas respond to salinity through different osmoregulatory mechanisms, which are organ- and cultivarspecific. Moreover, ABA is involved in the SOS pathway and prevention of $\mathrm{Na}^{+}$transport from roots to shoots through xylem (Zhu et al., 2017). Reduced ABA levels in Chinese cabbage roots, accompanied by a sharp increase in the $\mathrm{Na}^{+} / \mathrm{K}^{+}$ratio in leaves at the highest salinity, show that Chinese cabbage has less ability to control $\mathrm{Na}^{+}$leakage to shoots than the other two more tolerant cultivars.

In addition to ABA, JAs contribute to abiotic stress responses, although their roles in responses to biotic stress have received the most attention. There are also conflicting indications of their roles in salinity responses. Increases in JA levels following exposure to salinity, with associated increases in tolerance, have been recorded in several species, including tomato, iris, and rice (Wang et al., 2001; Pedranzani et al., 2003; Tani et al., 2008). However, impaired biosynthesis of the JA precursor OPDA reportedly enhances the stress tolerance of Arabidopsis aoc mutants by increasing ROS scavenging activity and delaying senescence. These mutants also reportedly accumulate less $\mathrm{Na}^{+}$ in shoots than wild type controls when exposed to salinity, while their roots' ion contents are not affected (Hazman et al., 2015). Similarly, we found that in leaves of more tolerant cultivars exposed to severe salinity, contents of JA-Ile (the most bioactive jasmonate) were lower than in corresponding controls, while JA-Ile levels in leaves of salt-sensitive Chinese cabbage were not influenced by salinity. Furthermore, Kurotani et al. (2015) found that the bioactive JAs negatively affect rice viability under salt stress in experiments with a transgenic mutant. Enhanced expression of CYP94C2b, which contributes to the conversion of bioactive JA-Ile to the inactive forms $12 \mathrm{OH}$-JA-Ile and $12 \mathrm{COOH}$ JA-Ile, did not affect natural senescence but delayed salt-induced senescence in an overexpressing rice mutant. The repression of JA-signaling is maintained at low levels of JA-Ile, while increases in its levels trigger JA-signaling (Wasternack and Strnad, 2016). Therefore, the considerably lower amounts of JA and JA-Ile we observed in leaves of white cabbage and kale may potentially contribute to a postponement of JA-mediated senescence in saline conditions.

The role of BRs in salt stress has been explored through monitoring effects of exogenous application of active BRs, which reportedly increases plants' tolerance, mainly through induction of $\mathrm{H}_{2} \mathrm{O}_{2}$ signaling and antioxidant machinery (Sharma et al., 2017). BRs can also mitigate some negative effects of salt stress on photosynthesis (Siddiqui et al., 2018). However, little is known about the roles of endogenous BRs in salinity stress responses. The Arabidopsis BR signaling impaired mutants BRdeficient det2-1 and BR-insensitive bin2-1 reportedly have higher sensitivity to salt stress during seed germination and seedling growth than wild type counterparts and have reduced levels of proline and transcripts of salt- and ABA-induced genes (Zeng et al., 2010). However, improved drought tolerance and delays in senescence during drought have been observed in transgenic creeping bentgrass (Agrostis stolonifera L.) with reduced levels of BRs (Han et al., 2017). Correlations between reduced levels of $\mathrm{BL}$ and improvements in drought tolerance have also been recorded in Arabidopsis plants (Northey et al., 2016). Moreover, we recently found that more $\mathrm{BL}$ accumulated in drought-sensitive Chinese cabbage than in the more tolerant kale and white cabbage in drought conditions (Pavlović et al., 2018b). Furthermore, a positive correlation between $\mathrm{ABA}$ and $\mathrm{BL}$ was noted. It is known that stomata closure can be mediated by BR and stress hormone (ABA, ethylene) crosstalk (Ha et al., 2016; Jiroutova et al., 2018), which may lead to reduced photosynthetic rates under salinity stress (Ashraf and Harris, 2013). Since photosynthesis was most strongly affected in Chinese cabbage, changes in BR levels could be linked to the osmotic component of salt stress. Accumulation of BRs was also observed in roots; kale accumulated three times more CS at the highest salinity while BL levels in Chinese cabbage were increased up to 60 -fold, depending on the treatment. The high accumulation of BL in this salt-sensitive cultivar correlates with its stronger inhibition of root growth observed in the root-growth bioassay. In addition, experiments with Arabidopsis bes1-D mutants, which have enhanced BR signaling, and treatment of wild type plants with high levels of BL, have revealed that BRs promote overall root growth inhibition (González-García et al., 2011). Maintenance of optimal levels of active BRs in roots may contribute to tolerance mechanisms since it has been proposed that BR signaling is temporarily inhibited in early phases of root growth response to salinity (Geng et al., 2013).

\section{CONCLUSION}

Based on our data, Chinese cabbage is the most sensitive, white cabbage moderately while kale the most tolerant to salinity stress among selected brassicas. Reductions in photosynthetic efficiency $\left(\mathrm{PI}_{\text {total }}\right)$ were observed in all three brassicas exposed to higher salt concentrations, indicating that salt stress reduced the capacity of the photosynthetic system for efficient energy conversion, particularly in Chinese cabbage. This is in agreement with biomass reduction upon prolonged salinity stress (7 days) which was the most prominent in Chinese cabbage, then in white cabbage and finally kale. ABA levels were enhanced in all three brassicas under salt stress which is consistent with control of transpiration in salinity responses through ABA-induced stomatal closure and associated reductions in photosynthetic rates. It was shown that more tolerant varieties were able to sustain or even increase their ABA levels, while those of the sensitive Chinese cabbage declined under the most severe salt conditions. Better tolerance of kale was accompanying with better ability to control $\mathrm{Na}^{+}$leakage from roots to shoots; $\mathrm{Na}^{+} / \mathrm{K}^{+}$ratio was high in root and low in leaves with low MDA level at the same time in comparison to more sensitive brassicas. Furthermore, the considerably lower amounts of JA and JA-Ile measured in leaves of more tolerant white cabbage and kale may potentially contribute to the postponement of 
JA-mediated senescence in saline conditions. Finally, enhanced salinity tolerance in selected brassicas is accompanying with a higher level of TY (precursor of active BRs) and lower level of active BL. The high accumulation of BL in salt-sensitive cultivar correlates with its stronger root growth inhibition and reduced photosynthetic rates under salinity stress.

To our knowledge, this is the first report on comparative research on some Brassica crops to gain insights into correlations between initial salinity tolerance and diverse physiological, biochemical and hormonal parameters in Brassicaceae. However, long-term exposure of Brassica crops to salinity stress need to be investigated and compared to these initial salt responses. Further molecular-level research is needed to establish more precise conclusions and global understanding of salinity tolerance in brassicas.

\section{AUTHOR CONTRIBUTIONS}

IP and BS-S designed the research. IP performed the salinity stress experiments, analyzed the levels of stress hormones, conducted the statistical and principle component analyses, and designed the figures. BS-S performed the root-growth bioassays and biomass production experiments. JO and DT performed the brassinosteroid instrumental and data analyses. ON and MS supervised all other hormonal measurements and data analysis. VVB and SRB performed the stress diagnostic experiments and data analysis. HL performed the photosynthesis measurements.

\section{REFERENCES}

Ahmad, P., Rasool, S., Gul, A., Sheikh, S. A., Akram, N. A., Ashraf, M., et al. (2016). Jasmonates: multifunctional roles in stress tolerance. Front. Plant Sci. 7:813. doi: $10.3389 /$ fpls.2016.00813

Almeida, D. M., Margarida Oliveira, M., and Saibo, N. J. M. (2017). Regulation of $\mathrm{Na}^{+}$and $\mathrm{K}^{+}$homeostasis in plants: towards improved salt stress tolerance in crop plants. Genet. Mol. Biol. 40, 326-345. doi: 10.1590/1678-4685-GMB-20160106

Almeida, P., Feron, R., de Boer, G. J., and de Boer, A. H. (2014). Role of $\mathrm{Na}^{+}, \mathrm{K}^{+}$, $\mathrm{Cl}^{-}$, proline and sucrose concentrations in determining salinity tolerance and their correlation with the expression of multiple genes in tomato. AoB Plants 6:plu039. doi: 10.1093/aobpla/plu039

Ashraf, M., and Harris, P. J. C. (2013). Photosynthesis under stressful environments: an overview. Photosynthetica 51, 163-190. doi: 10.1111/plb. 12014

Assaha, D. V. M., Ueda, A., Saneoka, H., Al-Yahyai, R., and Yaish, M. W. (2017). The role of $\mathrm{Na}^{+}$and $\mathrm{K}^{+}$transporters in salt stress adaptation in glycophytes. Front. Physiol. 8:509. doi: 10.3389/fphys.2017.00509

Begović, L., Mlinarić, S., Dunić, J. A., Katanić, Z., Lončarić, Z., Lepeduš, H., et al. (2016). Response of Lemna minor L. to short-term cobalt exposure: the effect on photosynthetic electron transport chain and induction of oxidative damage. Aquat. Toxicol. 175, 117-126. doi: 10.1016/j.aquatox.2016. 03.009

Chakraborty, K., Sairam, R. K., and Bhattacharya, R. C. (2012). Differential expression of salt overly sensitive pathway genes determines salinity stress tolerance in Brassica genotypes. Plant Physiol. Biochem. 51, 90-101. doi: 10. 1016/j.plaphy.2011.10.001

Chen, S., Yang, J., Zhang, M., Strasser, R. J., and Qiang, S. (2016). Classification and characteristics of heat tolerance in Ageratina adenophora populations using fast chlorophyll a fluorescence rise O-J-I-P. Environ. Exp. Bot. 122, 126-140. doi: 10.1016/j.envexpbot.2015.09.011
SM was responsible for analysis of photosynthesis data, statistics, and figure design. IP and SM drafted the manuscript. All authors discussed the results and implications, edited the manuscript, and approved the final manuscript.

\section{FUNDING}

This work was supported by the Croatian Science Foundation (Project No. IP-2014-09-4359), the Ministry of Education, Youth and Sports of the Czech Republic (European Regional Development Fund-Project "Plants as a tool for sustainable global development" No. CZ.02.1.01/0.0/0.0/16_019/0000827), and the Czech Science Foundation (Project No. 17-06613S).

\section{ACKNOWLEDGMENTS}

We thank Branimir Urlić, Ph.D., and MS Mara Bogović for providing kale and white cabbage seeds, respectively, used in this research and MS Ivan Petřik for assistance in performing phytohormone analysis.

\section{SUPPLEMENTARY MATERIAL}

The Supplementary Material for this article can be found online at: https://www.frontiersin.org/articles/10.3389/fpls.2019.00450/ full\#supplementary-material

Dąbrowski, P., Baczewska, A. H., Pawluśkiewicz, B., Paunov, M., Alexantrov, V., Goltsev, V., et al. (2016). Prompt chlorophyll a fluorescence as a rapid tool for diagnostic changes in PSII structure inhibited by salt stress in Perennial ryegrass. J. Photochem. Photobiol. B Biol. 157, 22-31. doi: 10.1016/j.jphotobiol.2016. 02.001

Duan, H., Zhu, Y., Qi, D., Li, W., Hua, X., Liu, Y., et al. (2012). Comparative study on the expression of genes involved in carotenoid and ABA biosynthetic pathway in response to salt stress in tomato. J. Integr. Agr. 11, 1093-1102. doi: 10.1016/S2095-3119(12)60102-6

Duarte, B., Cabrita, M. T., Gameiro, C., Matos, A. R., Godinho, R., Marques, J. C., et al. (2017). Disentangling the photochemical salinity tolerance in Aster tripolium L.: connecting biophysical traits with changes in fatty acid composition. Plant Biol. 19, 239-248. doi: 10.1111/plb.12517

Ellouzi, H., Ben Hamed, K., Hernández, I., Cela, J., Müller, M., Magné, C., et al. (2014). A comparative study of the early osmotic, ionic, redox and hormonal signaling response in leaves and roots of two halophytes and a glycophyte to salinity. Planta 240, 1299-1317. doi: 10.1007/s00425-014-2154-7

Fahad, S., Hussain, S., Matloob, A., Khan, F. A., Khaliq, A., Suad, S., et al. (2015). Phytohormones and plant responses to salinity stress: a review. Plant Growth Regul. 75, 391-404. doi: 10.1007/s10725-014-0013-y

Fiket, Ž., Mikac, N., and Kniewald, G. (2016). Mass fractions of forty-six major and trace elements, including rare earth elements, in sediment and soil reference materials used in environmental studies. Geostand. Geoanal. Res. 41, 123-135. doi: 10.1111/ggr.12129

Finkelstein, R. (2013). Abscisic acid synthesis and response. Arabidopsis Book 11:e0166. doi: 10.1199/tab.0166

Floková, K., Tarkowská, D., Miersch, O., Strnad, M., Wasternack, C., and Novák, O. (2014). UHPLC-MS/MS based target profiling of stress-induced phytohormones. Phytochemistry 105, 147-157. doi: 10.1016/j.phytochem.2014. 05.015

Geng, Y., Wu, R., Wee, C. W., Xie, F., Wei, X., Chan, P. M. Y., et al. (2013). A spatio-temporal understanding of growth regulation during the salt 
stress response in Arabidopsis. Plant Cell 25, 2132-2154. doi: 10.1105/tpc.113. 112896

Gharbi, E., Martínez, J. P., Benahmed, H., Hichri, I., Dobrev, P. I., Motyka, V., et al. (2017). Phytohormone profiling in relation to osmotic adjustment in $\mathrm{NaCl}$ treated plants of the halophyte tomato wild relative species Solanum chilense comparatively to the cultivated glycophyte Solanum lycopersicum. Plant Sci. 258, 77-89. doi: 10.1016/j.plantsci.2017.02.006

Goltsev, V., Kalaji, H., Paunov, M., Bąba, W., Horaczek, T., Mojski, J., et al. (2016). Variable chlorophyll fluorescence and its use for assessing physiological condition of plant photosynthetic apparatus. Russ. J. Plant Physiol. 63, 869-893. doi: 10.1134/S1021443716050058

González-García, M. P., Vilarrasa-Blasi, J., Zhiponova, M., Divol, F., MoraGarcia, S., Russinova, E., et al. (2011). Brassinosteroids control meristem size by promoting cell cycle progression in Arabidopsis roots. Development 138, 849-859. doi: 10.1242/dev.057331

Ha, Y., Shang, Y., and Nam, K. H. (2016). Brassinosteroids modulate ABA-induced stomatal closure in Arabidopsis. J. Exp. Bot. 67, 6297-6308. doi: 10.1093/jxb/ erw385

Han, J. Y., Kim, Y. S., Hwang, O. J., Roh, J., Ganguly, K., Kim, S. K., et al. (2017). Overexpression of Arabidopsis thaliana brassinosteroid-related acyltransferase 1 gene induces brassinosteroid-deficient phenotypes in creeping bentgrass. PLoS One 12:e0187378. doi: 10.1371/journal.pone.0187378

Hazman, M., Hause, B., Eiche, E., Nick, P., and Riemann, M. (2015). Increased tolerance to salt stress in OPDA-deficient rice ALLENE OXIDE CYCLASE mutants is linked to an increased ROS-scavenging activity. J. Exp. Bot. 66, 3339-3352. doi: 10.1093/jxb/erv142

Jajoo, A. (2014). "Changes in photosystem II heterogeneity in response to high salt stress," in Contemporary Problems of Photosynthesis, eds S. I. Allakhverdiev, A. B. Rubin, and V. A. Shuvalov (Izhevsk-Moscow: Institute of Computer Science), 397-413.

Jan, A. S., Shinwari, Z. K., and Rabbani, M. A. (2016). Morpho-biochemical evaluation of Brassica rapa sub-species for salt tolerance. Genetika 48, 323-338. doi: 10.2298/GENSR1601323J

Jiroutova, P., Okleskova, J., and Strnad, M. (2018). Crosstalk between brassinosteroids and ethylene during plant growth and under abiotic stress conditions. Int. J. Mol. Sci. 19:E3283. doi: 10.3390/ijms19103283

Julkowska, M. M., and Testerink, C. (2015). Tuning plant signaling and growth to survive salt. Trend Plant Sci. 20, 586-594. doi: 10.1016/j.tplants.2015.06.008

Kalaji, H. M., Bosa, K., Kościelniak, J., and Żuk-Gołaszewska, K. (2011). Effects of salt stress on photosystem II efficiency and CO2 assimilation of two Syrian barley landraces. Environ. Exp. Bot. 73, 64-72. doi: 10.1016/j.envexpbot.2010. 10.009

Kalaji, H. M., Račková, L., Paganová, V., Swoczyna, T., Rusinowski, S., and Sitko, K. (2017). Can chlorophyll a fluorescence parameters be used as bio-indicators to distinguish between drought and salinity stress in Tilia cordata mill? Environ. Exp. Bot. 152, 149-157. doi: 10.1016/j.envexpbot.2017.11.001

Kamboj, A., Ziemann, M., and Bhave, M. (2015). Identification of salt-tolerant barley varieties by a consolidated physiological and molecular approach. Acta Physiol. Plant. 37:1716. doi: 10.1007/s11738-014-1716-4

Krüger, G. H. J., De Villiers, M. F., Strauss, A. J., de Beer, M., van Heerden, P. D. R., Maldonado, R., et al. (2014). Inhibition of photosystem II activities in soybean (Glycine max) genotypes differing in chilling sensitivity. S. Afr. J. Bot. 95, 85-96. doi: 10.1016/j.sajb.2014.07.010

Kumar, G., Purty, R. S., Sharma, M. P., Singla-Pareek, S. L., and Pareek, A. (2009). Physiological responses among Brassica species under salinity stress show strong correlation with transcript abundance for SOS pathway-related genes. J. Plant Physiol. 166, 507-520. doi: 10.1016/j.jplph.2008.08.001

Kurotani, K. I., Hayashi, K., Hatanaka, S., Toda, Y., Ogawa, D., Ichikawa, H., et al. (2015). Elevated levels of CYP94 family gene expression alleviate the jasmonate response and enhance salt tolerance in rice. Plant Cell Physiol. 56, 779-789. doi: $10.1093 / \mathrm{pcp} / \mathrm{pcv006}$

Liang, W., Ma, X., Wan, P., and Liu, L. (2018). Plant salt-tolerance mechanism: a review. Biochem. Biophys. Res. Commun. 495, 286-291. doi: 10.1016/j.bbrc. 2017.11.043

Mancarella, S., Orsini, F., Van Oosten, M. J., Sanoubar, R., Stanghellini, C., Kondo, S., et al. (2016). Leaf sodium accumulation facilitates salt stress adaptation and preserves photosystem functionality in salt stressed Ocimum basilicum. Environ. Exp. Bot. 130, 162-173. doi: 10.1016/j.envexpbot.2016. 06.004

Mehta, P., Jajoo, A., Mathur, S., and Bharti, S. (2010). Chlorophyll a fluorescence study revealing effects of high salt stress on photosystem II in wheat leaves. Plant Physiol. Biochem. 48, 16-20. doi: 10.1016/j.plaphy.2009.10.006

Mittal, S., Kumari, N., and Sharma, V. (2012). Differential response of salt stress on Brassica juncea: photosynthetic performance, pigment, proline, D1 and antioxidant enzymes. Plant Physiol. Biochem. 54, 17-26. doi: 10.1016/j.plaphy. 2012.02.003

Munns, R., and Gilliham, M. (2015). Salinity tolerance of crops - what is the cost? New Phytol. 208, 668-673. doi: 10.1111/nph.13519

Munns, R., James, R. A., Gilliham, M., Flowers, T. J., and Colmer, T. D. (2016). Tissue tolerance: an essential but elusive trait for salt-tolerant crops. Funct. Plant Biol. 43, 1103-1113. doi: 10.1071/FP16187

Northey, J. G., Liang, S., Jamshed, M., Deb, S., Foo, E., Reid, J. B., et al. (2016). Farnesylation mediates brassinosteroid biosynthesis to regulate abscisic acid responses. Nat. Plants 2:16114. doi: 10.1038/nplants.2016.114

Oklestkova, J., Tarkowská, D., Eyer, L., Elbert, T., Marek, A., Smržová, Z., et al. (2017). Immunoaffinity chromatography combined with tandem mass spectrometry: a new tool for the selective capture and analysis of brassinosteroid plant hormones. Talanta 170, 432-440. doi: 10.1016/j.talanta.2017. 04.044

Oukarroum, A., Bussotti, F., Goltsev, V., and Kalaji, H. M. (2015). Correlation between reactive oxygen species production and photochemistry of photosystems I and II in Lemna gibba L. plants under salt stress. Environ. Exp. Bot. 109, 80-88. doi: 10.1016/j.envexpbot.2014.08.005

Pavlović, I., Pěnčík, A., Novák, O., Vujčić, V., Radić Brkanac, S., Lepeduš, H., et al. (2018a). Short-term salt stress in Brassica rapa seedlings causes alterations in auxin metabolism. Plant Physiol. Biochem. 125, 74-84. doi: 10.1016/j.plaphy. 2018.01.026

Pavlović, I., Petřik, I., Tarkowská, D., Lepeduš, H., Vujčić Bok, V., Radić Brkanac, S., et al. (2018b). Correlations between phytohormones and drought tolerance in selected Brassica crops: Chinese cabbage, white cabbage and kale. Int. J. Mol. Sci. 19:2866. doi: 10.3390/ijms19102866

Pedranzani, H., Racagni, G., Alemano, S., Miersch, O., Ramírez, I., Peña-Cortés, H., et al. (2003). Salt tolerant tomato plants show increased levels of jasmonic acid. Plant Growth Regul. 4, 149-158. doi: 10.1080/15592324.2016.1146847

Per, T. S., Khan, M. I. R., Anjum, N. A., Masood, A., Hussain, S. J., and Khan, N. A. (2018). Jasmonates in plants under abiotic stresses: crosstalk with other phytohormones matters. Environ. Exp. Bot. 145, 104-120. doi: 10.1016/j. envexpbot.2017.11.004

Puniran-Hartley, N., Hartley, J., Shabala, L., and Shabala, S. (2014). Salinityinduced accumulation of organic osmolytes in barley and wheat leaves correlates with increased oxidative stress tolerance: in planta evidence for cross-tolerance. Plant Physiol. Biochem. 83, 32-39. doi: 10.1016/j.plaphy.2014. 07.005

Purty, R. S., Kumar, G., Singla-Pareek, S. L., and Pareek, A. (2008). Towards salinity tolerance in Brassica: an overview. Physiol. Mol. Biol. Plants 14, 39-49. doi: 10.1007/s12298-008-0004-4

Radić, S., Cvjetko, P., Glavaš, K., Roje, V., Pevalek-Kozlina, B., and Pavlica, M. (2009). Oxidative stress and DNA damage in broad bean (Vicia faba L.) seedlings induced by thallium. Environ. Toxicol. Chem. 28, 189-196. doi: 10. 1897/08-188.1

Raja, V., Majeed, U., Kang, H., Andrabi, K. I., and John, R. (2017). Abiotic stress: interplay between ROS, hormones and MAPKs. Environ. Exp. Bot. 137, 142-157. doi: 10.1016/j.envexpbot.2017.02.010

Riemann, M., Dhakarey, R., Hazman, M., Miro, B., Kohli, A., and Nick, P. (2015). Exploring jasmonates in the hormonal network of drought and salinity. Front. Plant Sci. 6:1077. doi: 10.3389/fpls.2015.01077

Schansker, G., Tóth, S. Z., Holzwarth, A. R., and Garab, G. (2014). Chlorophyll a fluorescence: beyond the limits of the QA model. Photosyn. Res. 120, 43-58. doi: 10.1007/s11120-013-9806-5

Shannon, M. C., and Grieve, C. M. (1999). Tolerance of vegetable crops to salinity. Sci. Hortic. 78, 5-38. doi: 10.1016/S0304-4238(98)00189-7

Sharma, I., Kaur, N., and Pati, P. K. (2017). Brassinosteroids: a promising option in deciphering remedial strategies for abiotic stress tolerance in rice. Front. Plant Sci. 8:2151. doi: 10.3389/fpls.2017.02151 
Siddiqui, H., Hayat, S., and Bajguz, A. (2018). Regulation of photosynthesis by brassinosteroids in plants. Acta Physiol. Plant. 40:59. doi: 10.1007/s11738-0182639-2

Soshinkova, T. N., Radyukina, N. L., Korolkova, D. V., and Nosov, A. V. (2013). Proline and functioning of the antioxidant system in Thellungiella salsuginea plants and cultured cells subjected to oxidative stress. Russ. J. Plant Physiol. 60, 41-54. doi: 10.1134/S1021443713010093

Strasser, R. J., Srivastava, A., and Tsimilli-Michael, M. (2000). "The Fluorescence transient as a tool to characterize and screen photosynthetic samples," in Probing Photosynthesis: Mechanism, Regulation and Adaptation, eds M. Yunus, U. Pathre, and P. Mohanty (New York, NY: CRC), 445-483.

Strasser, R. J., Tsimilli-Michael, M., and Srivastava, A. (2004). "Analysis of the chlorophyll a fluorescence transient," in Chlorophyll a Fluorescence: A Signature of Photosynthesis, eds G. C. Papageorgiou and Govinjee (Dordrecht: Springer), 321-362. doi: 10.1007/978-1-4020-3218-9_12

Strizhov, N., Abrahám, E., Okrész, L., Blickling, S., Zilberstein, A., Schell, J., et al. (1997). Differential expression of two P5CS genes controlling proline accumulation during salt-stress requires $\mathrm{ABA}$ and is regulated by $\mathrm{ABA} 1, \mathrm{ABI} 1$ and AXR2 in Arabidopsis. Plant J. 12, 557-569. doi: 10.1046/j.1365-313X.1997. 00557.x

Surender Reddy, P., Jogeswar, G., Rasineni, G. K., Maheswari, M., Reddy, A. R., Varshney, R. K., et al. (2015). Proline over-accumulation alleviates salt stress and protects photosynthetic and antioxidant enzyme activities in transgenic sorghum [Sorghum bicolor (L.) Moench]. Plant Physiol. Biochem. 94, 104-113. doi: 10.1016/j.plaphy.2015.05.014

Tani, T., Sobajima, H., Okada, K., Chujo, T., Arimura, S. I., Tsutsumi, N., et al. (2008). Identification of the OsOPR7 gene encoding 12-oxophytodienoate reductase involved in the biosynthesis of jasmonic acid in rice. Planta 227, 517-526. doi: 10.1007/s00425-007-0635-7

Tomek, P., Lazár, D., Ilík, P., and Naus, J. (2001). On the intermediate steps between the $\mathrm{O}$ and $\mathrm{P}$ steps in chlorophyll a fluorescence rise measured at different intensities of exciting light. Funct. Plant Biol. 28, 1151-1160. doi: 10.1071/PP01065

Venkatesh, J., Upadhyaya, C. P., Yu, J.-W., Hemavathi, A., Kim, D. H., Strasser, R. J., et al. (2012). Chlorophyll a fluorescence transient analysis of transgenic potato overexpressing D-galacturonic acid reductase gene for salinity stress tolerance. Hortic. Environ. Biotechnol. 53, 320-328. doi: 10.1007/s13580-0120035- 1

Verma, V., Ravindran, P., and Kumar, P. P. (2016). Plant hormone-mediated regulation of stress responses. BMC Plant Biol. 16:86. doi: 10.1186/s12870-0160771-y

Verslues, P. E., and Bray, E. A. (2006). Role of abscisic acid (ABA) and Arabidopsis thaliana ABA-insensitive loci in low water potential-induced ABA and proline accumulation. J. Exp. Bot. 57, 201-212. doi: 10.1093/jxb/erj026
Wang, Y., Mopper, S., and Hasenstein, K. H. (2001). Effects of salinity on endogenous ABA, IAA, JA, and SA in Iris hexagona. J. Chem. Ecol. 27, 327-342. doi: 10.1023/A:1005632506230

Wasternack, C., and Strnad, M. (2016). Jasmonate signaling in plant stress responses and development - active and inactive compounds. N. Biotechnol. 33, 604-613. doi: 10.1016/j.nbt.2015.11.001

Witzel, K., Matros, A., Strickert, M., Kaspar, S., Peukert, M., Mühling, K. H., et al. (2014). Salinity stress in roots of contrasting barley genotypes reveals time-distinct and genotype-specific patterns for defined proteins. Mol. Plant 7, 336-355. doi: 10.1093/mp/sst063

Yusuf, M. A., Kumar, D., Rajwanshi, R., Strasser, R. J., Tsimilli-Michael, M., Govindjee, et al. (2010). Overexpression of g-tocopherol methyl transferase gene in transgenic Brassica juncea plants alleviates abiotic stress: physiological and chlorophyll a fluorescence measurements. Biochim. Biophys. Acta 1797, 1428-1438. doi: 10.1016/j.bbabio.2010.02.002

Zeng, H., Tang, Q., and Hua, X. (2010). Arabidopsis brassinosteroid mutants det21 and bin2-1 display altered salt tolerance. J. Plant Growth Regul. 29, 44-52. doi: 10.1007/s00344-009-9111-x

Zhang, X., Lu, G., Long, W., Zou, Y., Li, F., and Nishio, T. (2014). Recent progress in drought and salt tolerance studies in Brassica crops. Breed. Sci. 64, 60-73. doi: $10.1270 /$ jsbbs. 64.60

Zhu, M., Zhou, M., Shabala, L., and Shabala, S. (2017). Physiological and molecular mechanisms mediating xylem $\mathrm{Na}^{+}$loading in barley in the context of salinity stress tolerance. Plant Cell Environ. 40, 1009-1020. doi: 10.1111/pce. 12727

Żurek, G., Rybka, K., Pogrzeba, M., Krzyżak, J., and Prokopiuk, K. (2014). Chlorophyll a fluorescence in evaluation of the effect of heavy metal soil contamination on Perennial grasses. PLoS One 9:e91475. doi: 10.1371/journal. pone.0091475

Zushi, K., and Matsuzoe, N. (2017). Using of chlorophyll a fluorescence OJIP transients for sensing salt stress in the leaves and fruits of tomato. Sci. Hortic. 219, 216-221. doi: 10.1016/j.scienta.2017.03.016

Conflict of Interest Statement: The authors declare that the research was conducted in the absence of any commercial or financial relationships that could be construed as a potential conflict of interest.

Copyright (C) 2019 Pavlović, Mlinarić, Tarkowská, Oklestkova, Novák, Lepeduš, Vujčić Bok, Radić Brkanac, Strnad and Salopek-Sondi. This is an open-access article distributed under the terms of the Creative Commons Attribution License (CC BY). The use, distribution or reproduction in other forums is permitted, provided the original author(s) and the copyright owner(s) are credited and that the original publication in this journal is cited, in accordance with accepted academic practice. No use, distribution or reproduction is permitted which does not comply with these terms. 